\title{
Hidratación del cemento portland: estudio por diversas técnicas
}

La complejidad de la química del cemento es motivo de que aún hoy día permanezcan sin aclarar muchos procesos que transcurren durante el fraguado y posterior endurecimiento de la pasta.

La industria de la construcción precisa de un conocimiento técnico más sólido, ya que al saber el modo de actuar de los componentes de la pasta del cemento puede conseguir de este material: facilidad y economía en su empleo, resistencias mecánicas elevadas e inalterabilidad y duración en las obras realizadas. Cualquier nuevo conocimiento sobre la química de la pasta, por ello, suele tener inmediata aplicación o sirve como base para ulteriores investigaciones, que en su día darán nuevas propiedades prácticas al cemento o incluso a otros materiales diferentes.

El comportamiento de la pasta durante las primeras 24 horas ha sido el motivo de este estudio. Se efectuaron medidas térmicas, de conductividad, de contenidos de productos solubles en agua, de productos cristalinos y de variaciones de solicitación de agua, por los métodos que veremos a continuación:

\section{METODOS}

\subsection{Preparación de las pastas y medidas físicas}

El amasado se efectuó con guantes de goma durante 2 minutos y medio. De acuerdo con la norma, se emplearon siempre $500 \mathrm{~g}$ de cemento y la cantidad de agua indicada en cada caso. La pasta obtenida se trasladó al interior de un molde troncocónico rígido normalizado soportado sobre su base mayor en una lámina de plástico. En el interior de la pasta se sumergen:

- Cinco termopares cobre-constantán conectados en serie (para medir la temperatura) (1). Los electrodos son dos láminas de acero inoxidable de $1 \mathrm{~mm}$ de espesor, de forma cuadrada de $40 \times 40 \mathrm{~mm}$, distanciadas $10 \mathrm{~mm}$ mediante un bloque de plexiglás que actúa de soporte y separador, con la misión de obtener la medida de la resistencia de la pasta $(2,3,4)$.

- Un bloque de yeso (constituido por dos electrodos: uno interior, de cable recto, y otro exterior cilíndrico, de tela metálica, ambos estañados).

El electrodo recto de cable se situó como eje del cilindro, de forma que no se tocasen, y se rellenó el hueco de escayola. Dentro de un molde cilíndrico de mayor diámetro se introdujo el conjunto anterior, que se recubrió a su vez de escayola (5). El bloque de yeso se 
mantuvo en agua hasta el momento de su empleo; se utilizó para observar las solicitaciones de agua de la pasta. Los terminales de los electrodos y termopares se llevaron a un aparato automático, que efectuó el registro durante la hidratación de la pasta (6). De las gráficas resultantes, por corrección de la resistencia en función de la temperatura (7), se obtuvieron las series de figuras del 1 al 6, del 13 al 15 y la 19, así como los datos que se describen en el cuadro I. El fraguado según Vicat, se determinó de acuerdo con la norma (8).

\subsection{Difracción de rayos $\mathbf{X}$}

Se empleó un aparato Philips PW-1.540, de $1 \mathrm{kw}$. En los difractogramas que figuran en este trabajo vienen descritas las condiciones de registro y de utilización del aparato de difracción de rayos $\mathrm{X}$.

\subsubsection{Preparación de las muestras}

A intervalos variables, indicados en los cuadros II y III, se obtuvieron extractos acuosos de las pastas hidratadas de la siguiente forma: de la pasta contenida en el molde, citado en el apartado 1.1., después de eliminar unos $2 \mathrm{~mm}$ en espesor de la capa superficial para no involucrar en el resultado de los análisis la influencia de posibles fenómenos de carbonatación y exudación (9), se separa una cantidad de pasta, de la que se pesan $10 \mathrm{~g}$. La muestra se introduce en un vaso de $250 \mathrm{ml}$, de forma alta, que contiene $125 \mathrm{ml}$ de agua destilada y un índice magnético recubierto de teflon, y se sitúa el vaso sobre un agitador magnético, que pone la muestra en suspensión; se mantiene así durante 5 min y se filtra sobre un filtro de banda blanca número 240, en un matraz aforado de $100 \mathrm{ml}$, que ya contiene $5 \mathrm{ml}$ de ácido clorhídrico concentrado. Mientras dura la filtración, la suspensión aún no filtrada se mantiene en agitación. Cuando ha filtrado la mitad de la suspensión contenida en el filtro se añade más, y así hasta conseguir el enrase del matraz. Se traslada el embudo sobre un tubo de ensayo sobre el que se continúa la filtración hasta que pase todo el líquido $\mathrm{y}$, finalmente, se tapa con un tapón de goma.

El ácido se añade con objeto de poner la disolución en igualdad de condiciones a la serie patrón empleada en fotometría, y sobre todo para evitar fluctuaciones en los contenidos de calcio producidas por carbonatación del hidróxido cálcico.

\begin{tabular}{|c|c|c|c|c|c|c|c|c|c|c|c|}
\hline \multicolumn{2}{|c|}{ Composición de la } & \multirow{2}{*}{$\begin{array}{c}\text { pasta } \\
\begin{array}{c}\text { Agua } \\
(\mathbf{m} l)\end{array}\end{array}$} & \multirow{2}{*}{$\begin{array}{c}\begin{array}{c}\text { Temp. } \\
\text { ambiente }\end{array} \\
\text { ToC }\end{array}$} & \multirow{2}{*}{$\begin{array}{l}\text { Primer } \\
\text { ToC }\end{array}$} & \multirow{2}{*}{$\begin{array}{c}\text { máximo } \\
\text { Tiempo } \\
\text { (min) }\end{array}$} & \multirow{2}{*}{$-\frac{\text { Primer }}{\begin{array}{c}\text { Resist. } \\
\text { (ohmios) }\end{array}}$} & \multirow{2}{*}{$\begin{array}{c}\text { mínimo } \\
\begin{array}{c}\text { Tiempo } \\
(\min )\end{array}\end{array}$} & \multirow{2}{*}{$\begin{array}{c}\text { Segundo } \\
\text { ToC }\end{array}$} & \multirow{2}{*}{$\begin{array}{c}\text { máximo } \\
\begin{array}{c}\text { Tiempo } \\
(\mathrm{min})\end{array}\end{array}$} & \multirow{2}{*}{$\begin{array}{c}\begin{array}{c}\text { Fraguado } \\
\text { Vicat }\end{array} \\
\begin{array}{c}\text { Tiempo } \\
\text { (min) }\end{array}\end{array}$} & Figuras \\
\hline $\begin{array}{c}\text { Clínker } \\
(\mathbf{g})\end{array}$ & $\begin{array}{c}\text { Yeso } \\
\text { (g) }\end{array}$ & & & & & & & & & & Núms. \\
\hline
\end{tabular}

\subsection{Determinaciones químicas}

Del matraz de $100 \mathrm{ml}$ se obtienen las muestras para análisis del $\mathrm{SO}_{3}$ (8), $\mathrm{CaO}$ (10) y álcalis (11). 


\subsubsection{Determinación de la alcalinidad total}

$20 \mathrm{ml}$ de la muestra del tubo de ensayo, mantenidos a ebullición, se valoraron con ácido clorhídrico $0,02 \mathrm{~N}$ y con rojo de metilo como indicador.

\subsubsection{Determinación de la alúmina soluble}

Como las muestras no tenían hierro detectable, se valoró colorimétricamente por el método del aluminón: después de ajustado el $\mathrm{pH}=5$, a $25 \mathrm{ml}$ de la muestra se añadieron $4 \mathrm{ml}$ de una disolución reguladora de acetato amónico-ácido acético $(300 \mathrm{~g} / l-12 \mathrm{ml} / \mathrm{l})$ y $4 \mathrm{ml}$ de aluminón (al $0,1 \%$ en agua destilada) y se enrasó la muestra a $50 \mathrm{ml}$ con agua destilada.

El matraz aforado de $50 \mathrm{ml}$ se calienta durante 1 hora en el baño de vapor para estabilizar el color; se enfría y compara con una serie patrón, que se preparó simultáneamente en igualdad de condiciones, que contiene en matraces aforados de $100 \mathrm{ml}: 0,2,5,8$ y $10 \mathrm{ml}$, de una disolución de aluminio de 5 p.p.m.; se empleó como colorímetro el fotómetro Beckman D.U., en la longitud de onda de 546 milimicras, con una rendija de 0,015 mm y una sensibilidad para el fotomultiplicador de 1.

\subsubsection{Determinación de la sílice soluble}

Se hizo una disolución nodriza por fusión en un crisol de níquel de $100 \mathrm{mg}$ de cuarzo y $1,5 \mathrm{~g}$ de $\mathrm{NaOH}$; el producto resultante se disolvió en $6 \mathrm{ml}$ de $\mathrm{ClH}$ concentrado y se llevó a un matraz aforado de $1.000 \mathrm{ml}$ y enrasó con agua desionizada; a una serie de matraces aforados de $100 \mathrm{ml}$ se les añadieron: 0, 5, 10, 15, 20 y $25 \mathrm{ml}$ de la disolución nodriza, y a cada uno $15 \mathrm{ml}$ de disolución de molibdato amónico y $5 \mathrm{ml}$ de ácido clorhídrico concentrado y se enrasaron con agua desionizada.

$25 \mathrm{ml}$ de la muestra se trataron con $15 \mathrm{ml}$ de disolución de molibdato amónico (al $20 \%$ en agua desionizada) y se añadieron con agitación $3,75 \mathrm{ml}$ de ácido clorhídrico concentrado y enrasó a $100 \mathrm{ml}$. Se esperó durante 1 hora hasta estabilización del color y se comparó éste con el de la serie patrón en el colorímetro Beckman D.U., a la longitud de onda de 436 milimicras, con una sensibilidad de 4 y una rendija de $0,18 \mathrm{~mm}$.

\subsubsection{Determinación del agua libre}

Una muestra de $5 \mathrm{~g}$ de pasta hidratada, previamente pulverizada, se introduce en un depósito con cierre hermético, provisto de un manómetro calibrado en porcentaje de agua. Se añade carburo de calcio y unos $40 \mathrm{~g}$ de perdigones de $1 \mathrm{~mm}$ de diámetro.

Se agita durante media hora para que se desprenda acetileno, por reacción del carburo con el agua libre de la pasta, actuando los perdigones como coadyuvantes de la pulverización y mezcla íntima de ésta con el carburo.

\subsubsection{Determinación del $p H$}

En el líquido del tubo se efectuó la determinación del pH con un pH-metro Philips PR9.403, previamente constrastado con disoluciones tampón de $\mathrm{pH}$ conocido. 


\section{RESULTADOS}

Los análisis químicos de los clínkeres utilizados y sus características principales vienen dados en el cuadro IV.

Los resultados obtenidos por las distintas técnicas vienen expresados generalmente, en los cuadros II y III, en g/125 $\mathrm{ml}$ (para llevarlos a g/l se multiplicarán por ocho).

\subsection{Resultados de la hidratación con el clínker $\mathbf{H}$}

Las curvas de la resistencia eléctrica y de las variaciones térmicas obtenidas por registro gráfico son las correspondientes a las figuras $1,2,3,4,5$ y 6 , en las cuales también está la curva de la resistencia eléctrica corregida en función de la temperatura.
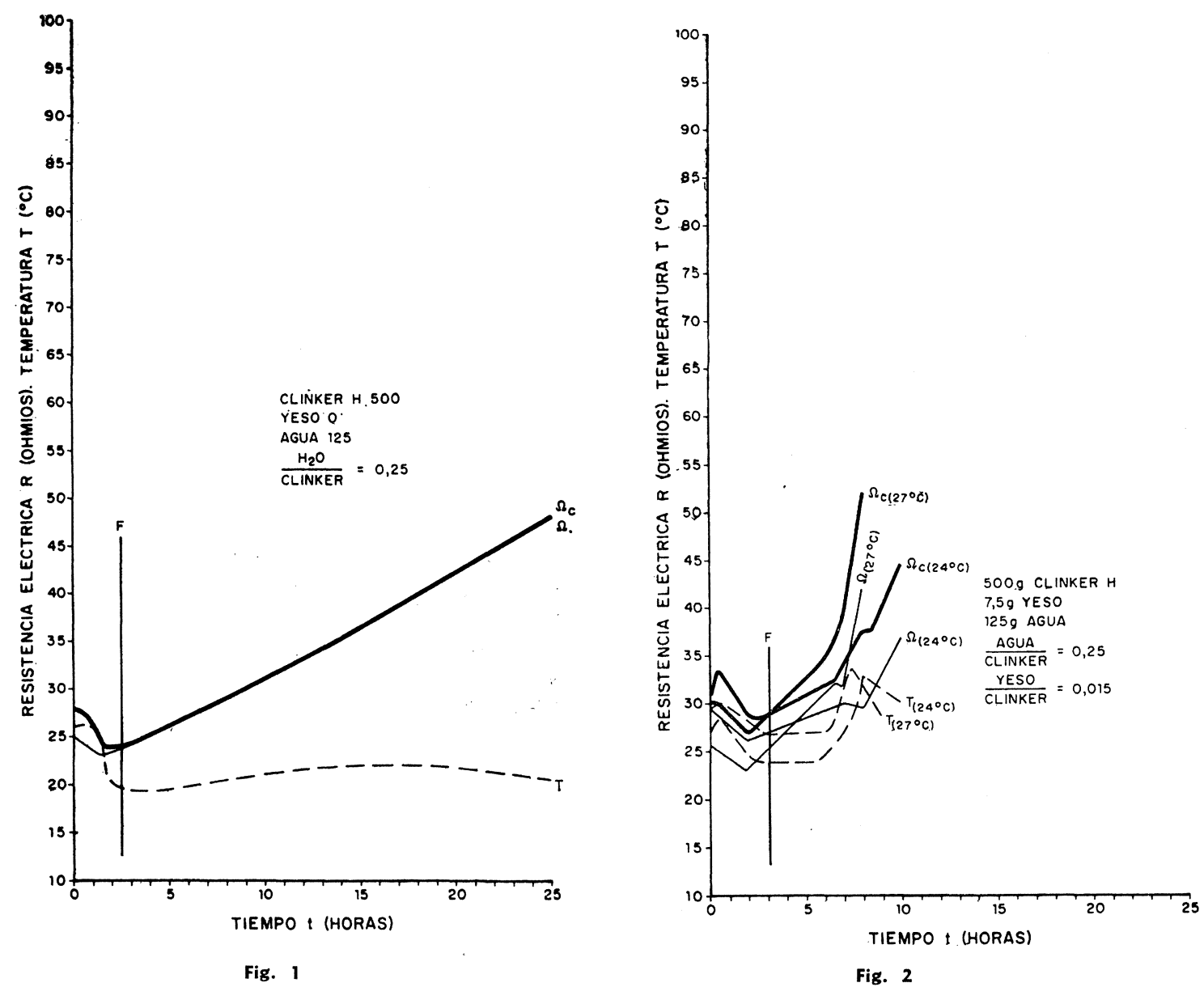

Fig. 2

Durante las primeras 4 horas de hidratación, las curvas que representa la resistencia eléctrica muestran un descenso; después de alcanzar un mínimo, los valores se hacen más elevados y la curva tiene una pendiente casi constante hasta que se presenta el segundo ciclo térmico; entonces aparece un mínimo y/o aumenta la pendiente.

La pendiente de la segunda rama de la curva se hace mayor al aumentar la temperatura del ambiente en donde se realiza la hidratación y al crecer la relación yeso-cemento. La movilidad iónica de la fase líquida de la pasta se facilita para determinadas temperaturas y concentraciones de yeso en cada cemento; en la curva de las resistencias eléctricas-tiempo de determinados tipos de cemento durante el segundo ciclo térmico, coincidiendo con su máxima temperatura, se observa la aparición de un mínimo. En otras ocasiones solamente se aprecia un cambio (aumento) de pendiente. 
RESISTENCIA ELECTRICA R (OHMIOS). TEMPERATURA I $\left({ }^{\circ} \mathrm{C}\right)$
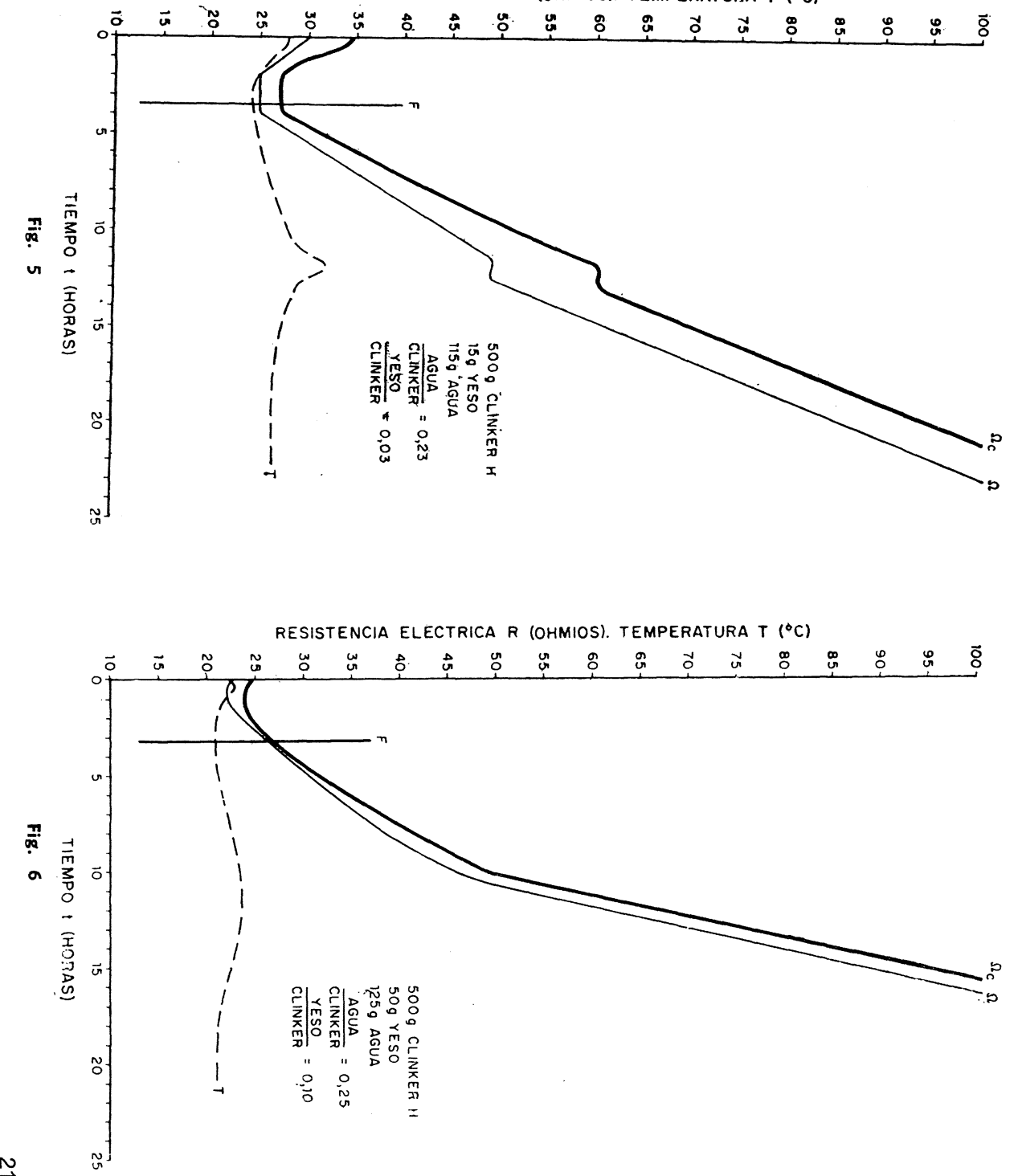

每

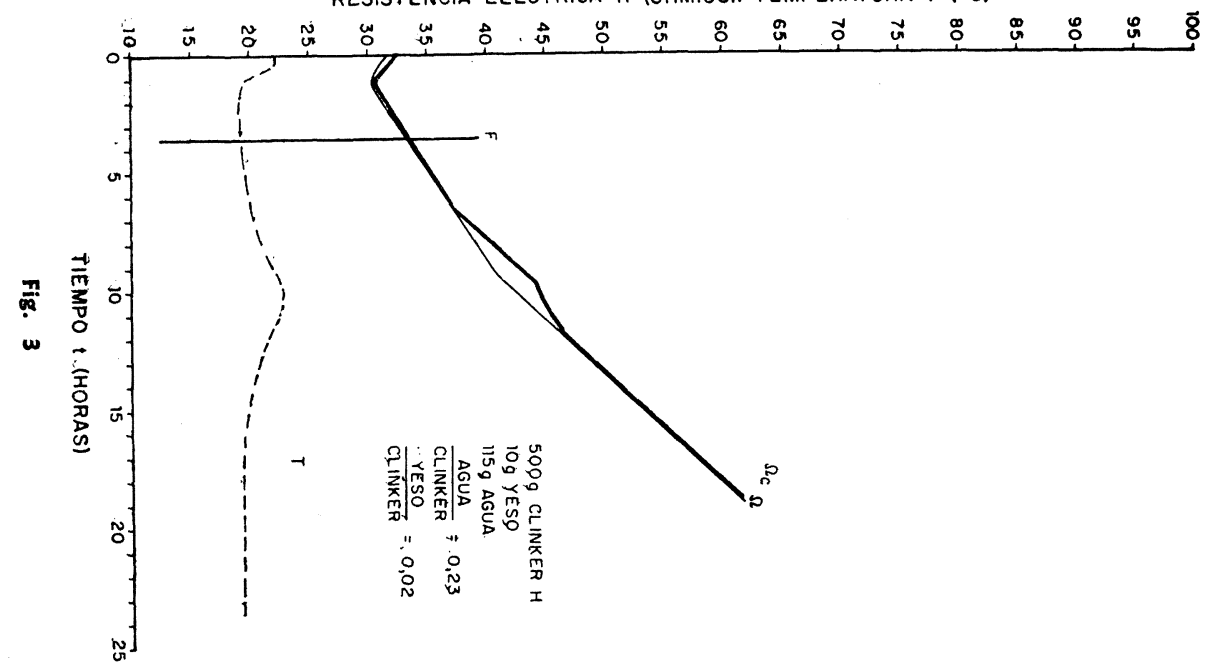

RESISTENCIA ELECTRICA R (OHMIOS) TEMPERATURA T $\left(^{\circ} \mathrm{C}\right)$

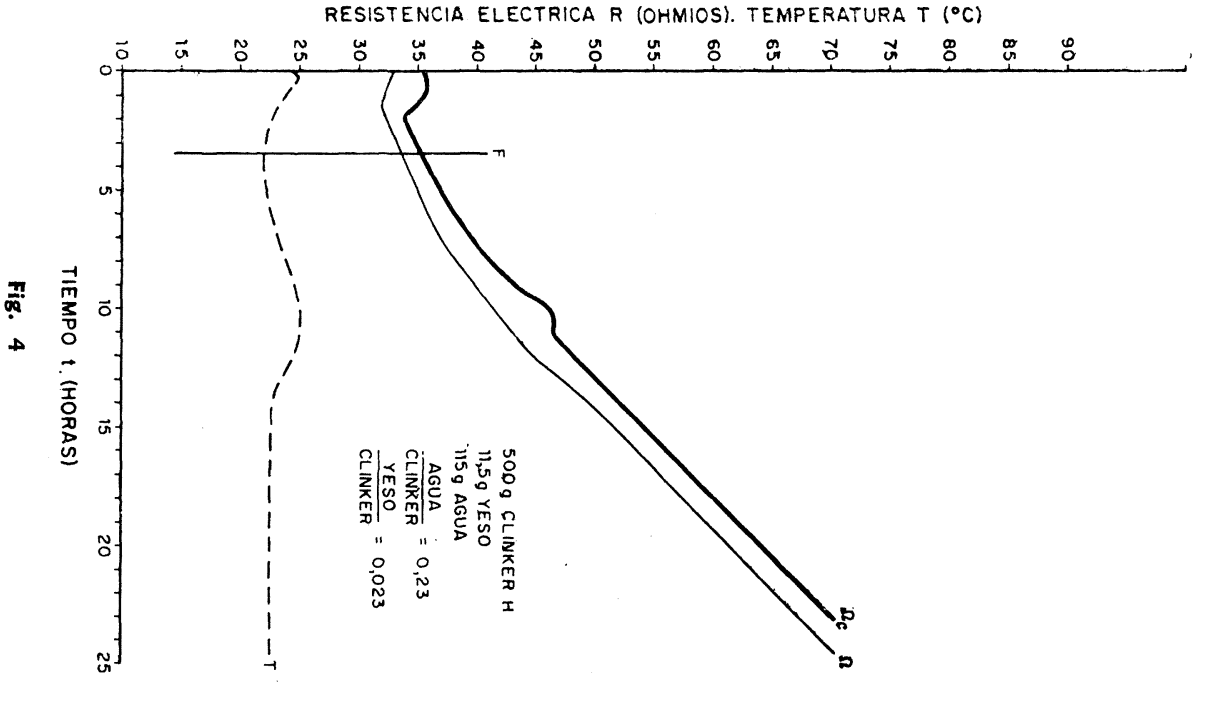




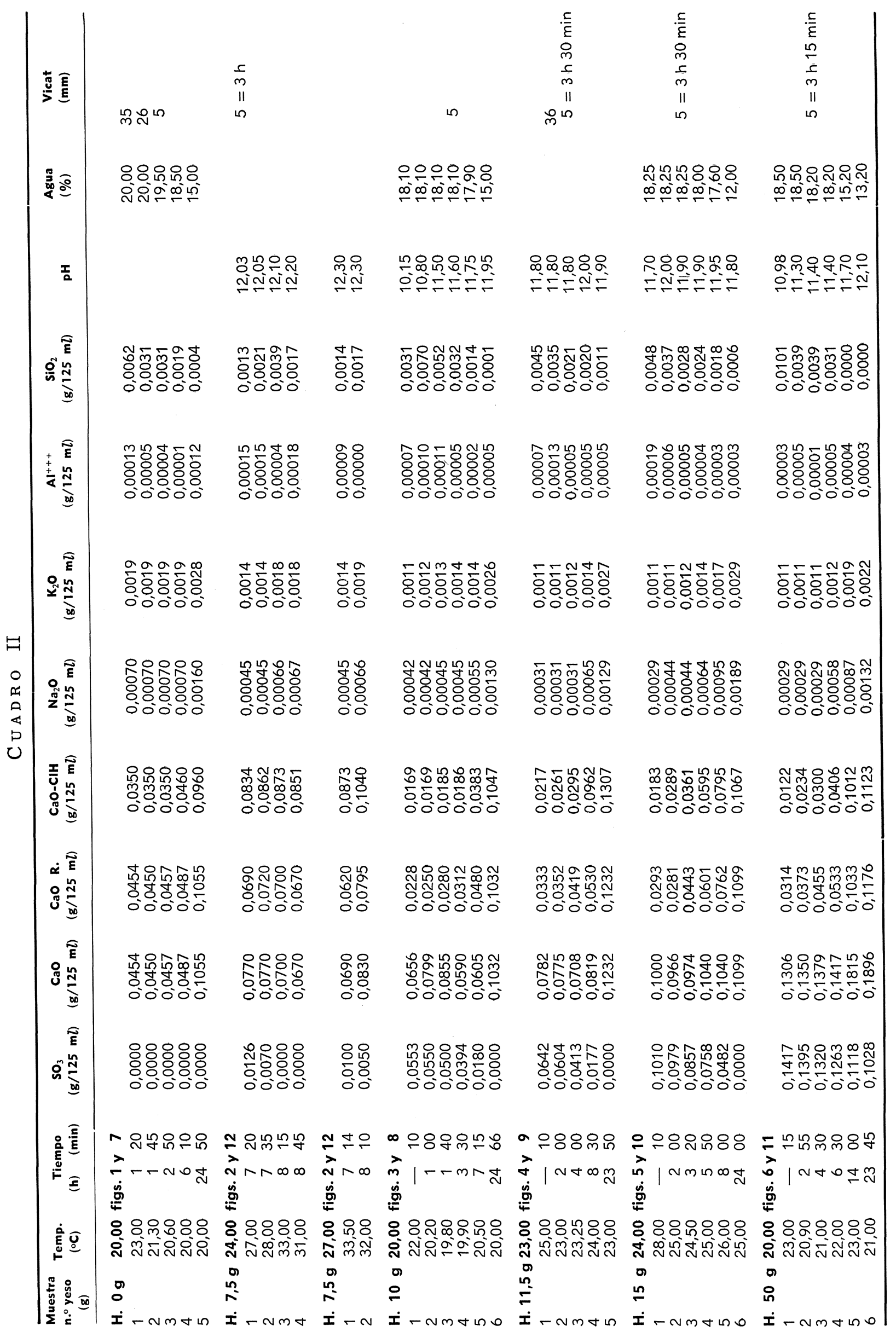




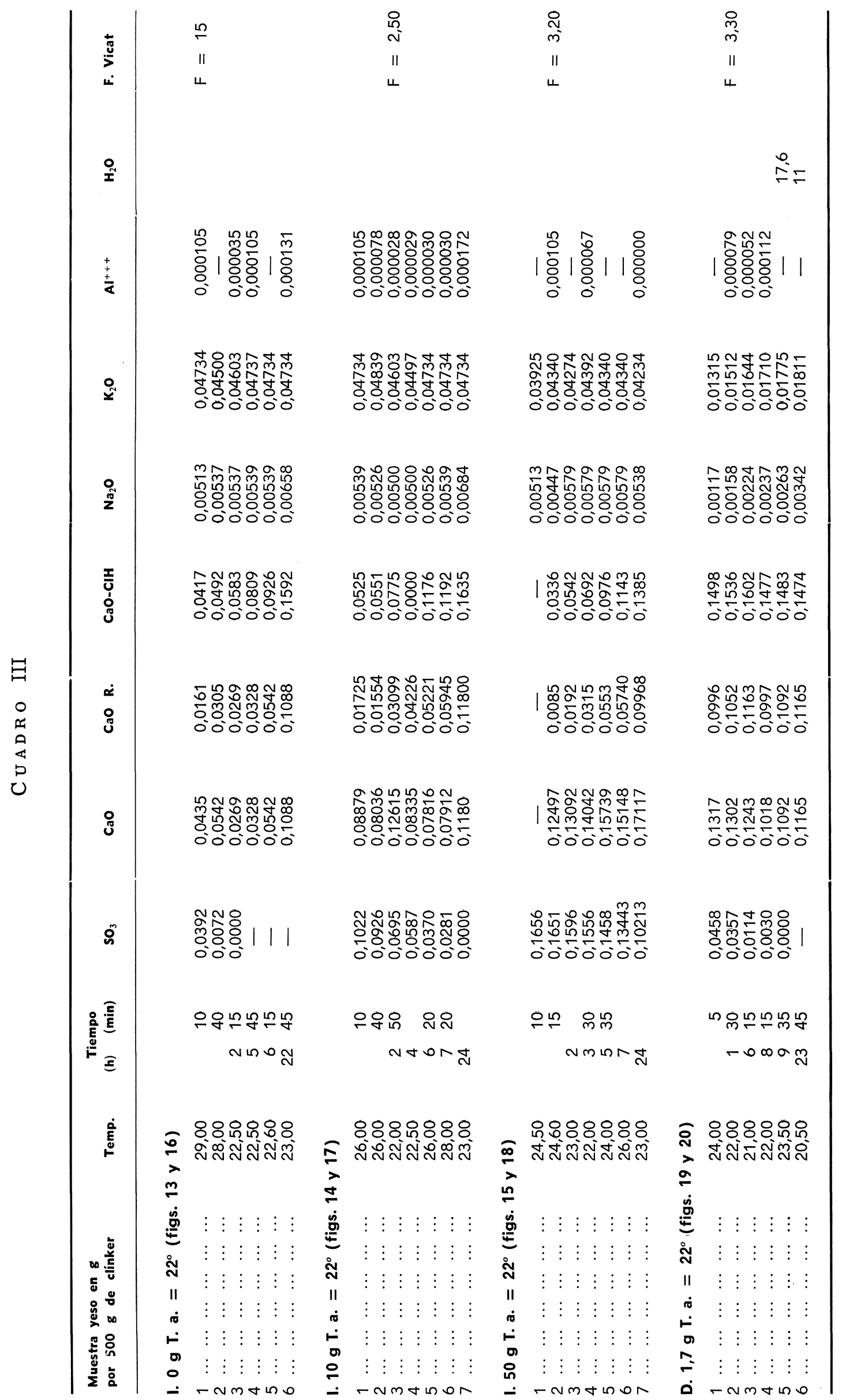


CUADRO IV

\begin{tabular}{|c|c|c|c|c|c|}
\hline & & Clínker I & Clínker $H^{*}$ & Cemento D & Cemento $A^{* * *}$ \\
\hline 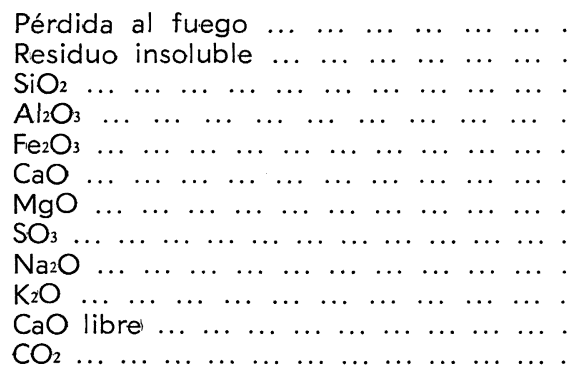 & $\begin{array}{l}\cdots \\
\cdots \\
\cdots \\
\cdots \\
\cdots \\
\cdots \\
\cdots \\
\cdots \\
\cdots \\
\cdots \\
\cdots\end{array}$ & $\begin{array}{r}0,89 \\
0,39 \\
20,34 \\
6,77 \\
3,56 \\
64,22 \\
2,15 \\
0,89 \\
0,14 \\
0,65 \\
0,05 \\
0,41\end{array}$ & $\begin{array}{r}1,40 \\
1,53 \\
24,50 \\
4,70 \\
2,50 \\
63,20 \\
4,12 \\
0,00 \\
0,07 \\
0,19 \\
\overline{0,26}\end{array}$ & $\begin{array}{r}3,20 \\
1,60 \\
20,20 \\
5,80 \\
2,70 \\
64,40 \\
2,40 \\
1,20 \\
0,24 \\
0,71 \\
0,22 \\
-\end{array}$ & $\begin{array}{l}E \\
= \\
= \\
\bar{E} \\
\bar{E} \\
\overline{-}\end{array}$ \\
\hline $\begin{array}{lllllllllll}\mathrm{C}_{3} \mathrm{~S} & \text { Bogue } & \ldots & \ldots & \ldots & \ldots & \ldots & \ldots & \ldots & \ldots & . \\
\mathrm{C}_{2} \mathrm{~S} & \text { Bogue } & \ldots & \ldots & \ldots & \ldots & \ldots & \ldots & \ldots & \ldots & . \\
\mathrm{C}_{3} \mathrm{~A} & \text { Bogue } & \ldots & \ldots & \ldots & \ldots & \ldots & \ldots & \ldots & \ldots & . \\
\mathrm{C}_{4} \mathrm{AF} & \text { Bogue } & \ldots & \ldots & \ldots & \ldots & \ldots & \ldots & \ldots & \ldots\end{array}$. & $\begin{array}{l}\cdots \\
\cdots \\
\cdots \\
\cdots\end{array}$ & $\begin{array}{l}55,77 \\
16,27 \\
11,92 \\
10,82\end{array}$ & $\begin{array}{r}35,80 \\
43,30 \\
8,20 \\
7,60\end{array}$ & $\begin{array}{r}53,37 \\
17,65 \\
10,80 \\
8,22\end{array}$ & E \\
\hline $\begin{array}{lcccccccc}\mathrm{SO}_{4} \mathrm{Ca} & \text { calculado } & \ldots & \ldots & \ldots & \ldots & \ldots & \ldots & \\
\mathrm{SO}_{4} \mathrm{Na}_{2} \text { calculado } & \ldots & \ldots & \ldots & \ldots & \ldots & \ldots & . \\
\mathrm{SO}_{4} \mathrm{~K}_{2} & \text { calculado } & \ldots & \ldots & \ldots & \ldots & \ldots & \ldots & .\end{array}$ & $\begin{array}{l}\cdots \\
\cdots \\
\cdots\end{array}$ & $\begin{array}{l}0,26 \\
0,32 \\
1,20\end{array}$ & $\begin{array}{l}0,00 \\
0,00 \\
0,00\end{array}$ & $\overline{-}$ & E \\
\hline $\begin{array}{lrlllllll}\mathrm{C}_{3} \mathrm{~S} & \text { microscopio } & \ldots & \ldots & \ldots & \ldots & \ldots & \ldots & . \\
\mathrm{C}_{2} \mathrm{~S} & \text { microscopio } & \ldots & \ldots & \ldots & \ldots & \ldots & \ldots & . \\
\mathrm{C}_{3} \mathrm{~A} & \text { microscopio } & \ldots & \ldots & \ldots & \ldots & \ldots & \ldots & . \\
\mathrm{C}_{4} \mathrm{AF} & \text { microscopio } & \ldots & \ldots & \ldots & \ldots & \ldots & \ldots & .\end{array}$ & $\begin{array}{l}\cdots \\
\cdots \\
\cdots \\
\cdots\end{array}$ & $\begin{array}{r}66,70 \\
14,70 \\
9,20 \\
8,90\end{array}$ & $\begin{array}{r}48,30 \\
34,20 \\
10,30 \\
7,20\end{array}$ & $\begin{array}{r}62,20 * * * \\
22,90 * * * \\
10,40 * * * \\
4,20 * * *\end{array}$ & $\overline{-}$ \\
\hline $\begin{array}{l}\text { Principio de fraguado } \\
\text { Fin de fraguado } \\
\text { Fin }\end{array}$ & $\begin{array}{l}\cdots \\
\cdots\end{array}$ & $15 \min$ & $\begin{array}{l}5 \mathrm{~h} 05 \mathrm{~min} \\
6 \mathrm{~h} 40 \mathrm{~min}\end{array}$ & $\begin{array}{l}4 \text { h } 35 \mathrm{~min} \\
6 \text { h } 50 \mathrm{~min}\end{array}$ & $\begin{array}{l}2 \text { h } 00 \text { min } \\
6 \text { h } 50 \mathrm{~min}\end{array}$ \\
\hline 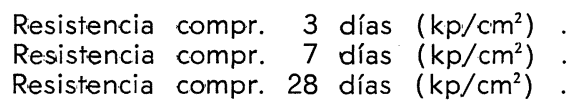 & $\begin{array}{l}\cdots \\
\cdots \\
\cdots\end{array}$ & - & $\begin{array}{l}\overline{233} \\
381\end{array}$ & $\begin{array}{l}229 \\
345 \\
462\end{array}$ & $\begin{array}{l}294 \\
373 \\
504\end{array}$ \\
\hline $\begin{array}{lllll}\text { Resistencia flexión } 3 \text { días } & \left(\mathrm{kp} / \mathrm{cm}^{2}\right) & \text {. } \\
\text { Resistencia flexión } 7 \text { días } & \left(\mathrm{kp} / \mathrm{cm}^{2}\right) & \text {. } \\
\text { Resistencia flexión } 28 \text { días } & \left(\mathrm{kp} / \mathrm{cm}^{2}\right)\end{array}$ & $\begin{array}{l}\cdots \\
\cdots \\
\cdots\end{array}$ & $\overline{-}$ & $\begin{array}{l}\overline{47} \\
61\end{array}$ & $\begin{array}{l}49 \\
64 \\
78\end{array}$ & $\begin{array}{l}65 \\
78 \\
88\end{array}$ \\
\hline 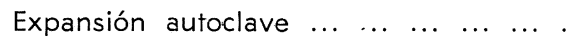 & $\ldots$ & - & expansivo & 0,39 & 0,08 \\
\hline
\end{tabular}

* Para las pruebas físicas se añadió un $3 \%$ de yeso.

** El cemento A es una mezcla de clínker 1 , al que se le añadió el $2,21 \%$ de yeso para las pruebas físicas y otras proporciones para distintasi pruebas.

*** Los valores corresponden a gránulos de clínker separados del cemento por tamizado y debido a una deficiente molturación por probable avería o mal funcionamiento de los separadores del molino de fábrica.

Para el clínker H, cuando la pasta no tiene yeso, la pendiente de la segunda rama de la curva de resistencia-tiempo se mantenía constante hasta las 24 horas que duraba el ensayo; las variaciones de temperatura eran mínimas.

Cuando a los $500 \mathrm{~g}$ de cemento empleados en el ensayo se les añadían 7, 5, 10, 11,5 y $15 \mathrm{~g}$ de yeso, para temperaturas comprendidas entre $23^{\circ}$ y $24^{\circ} \mathrm{C}$, aparecía un mínimo de resistencia eléctrica durante el segundo ciclo térmico, con temperaturas del orden de los $23^{\circ} \mathrm{C}$.

Como al efectuar las correcciones de resistencia eléctrica en función de la temperatura se descarta el efecto térmico y la aparición del mínimo se daba durante el segundo ciclo térmico, cuando sus temperaturas máximas eran relativamente elevadas y estaban agrupadas en un entorno muy cerrado, se sospechó que la formación del mínimo estaba muy relacionada con la rapidez de la reacción que transcurría durante el segundo ciclo térmico.

\subsubsection{Medidas de humedad con el bloque de yeso}

Los valores de las resistencias eléctricas de los bloques de yeso, y que representan las variaciones de la humedad en éstos, son muy elevados y caen fuera de las escalas utilizadas en las gráficas en que se representan las resistencias eléctricas y las variaciones de 
los análisis de los extractos acuosos de las pastas durante su hidratación. En consecuencia, las curvas que representan las resistencias debidas a dichas variaciones de humedad son meramente indicativas y no se relacionan con los valores del eje de ordenadas en las correspondientes figuras.

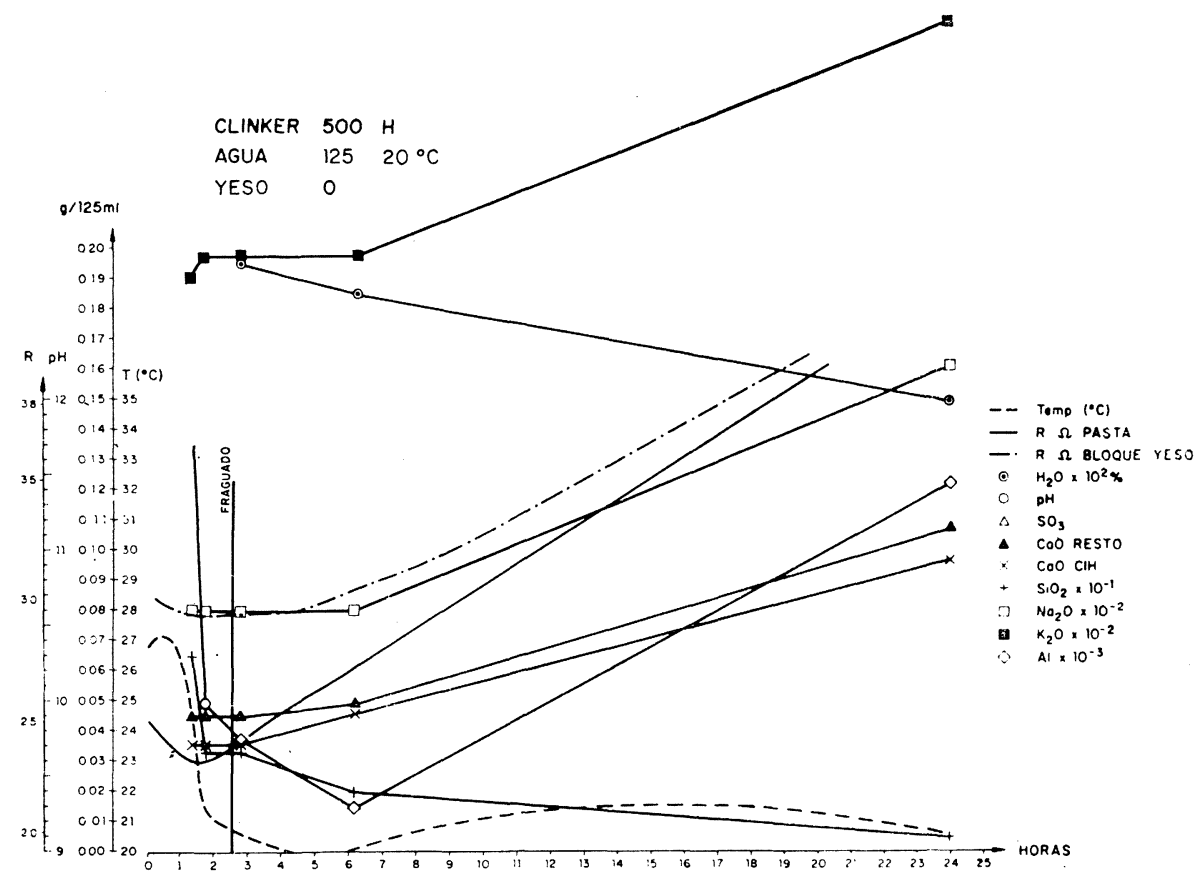

Fig. 7

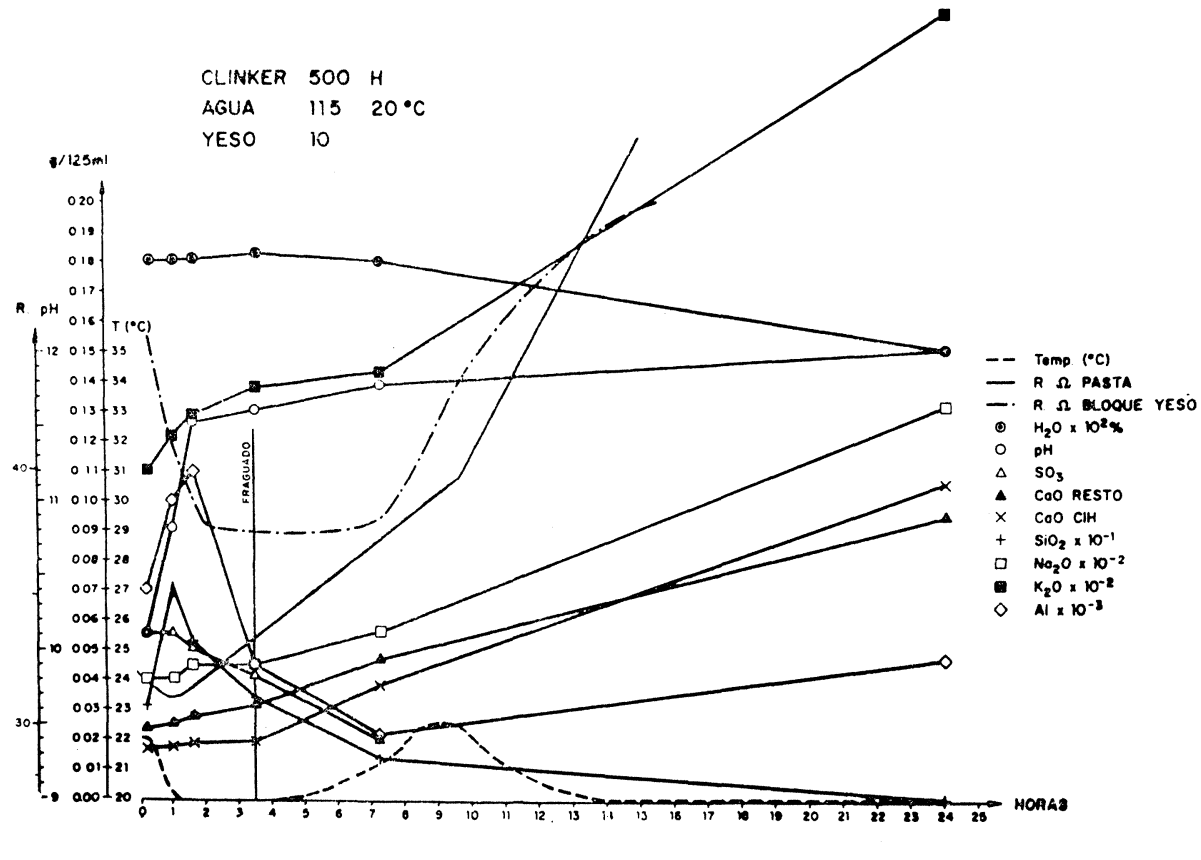

Fig. 8

En el caso de la pasta sin yeso (fig. 7), la línea representativa de la humedad tiene poca curvatura, y a partir del fin del fraguado, medido con la aguja de Vicat, manifiesta una subida lenta, que indica pérdida de agua en el bloque de yeso, solicitada por la pasta para su hidratación; la pendiente de la línea muestra la pequeña velocidad del proceso. 
Al aumentar la proporción de yeso en la pasta (figuras 8, 9, 10 y 11), las curvas presentan forma de $\mathrm{U}$; la primera rama desciende durante más tiempo cuanto mayor yeso contenga la pasta.

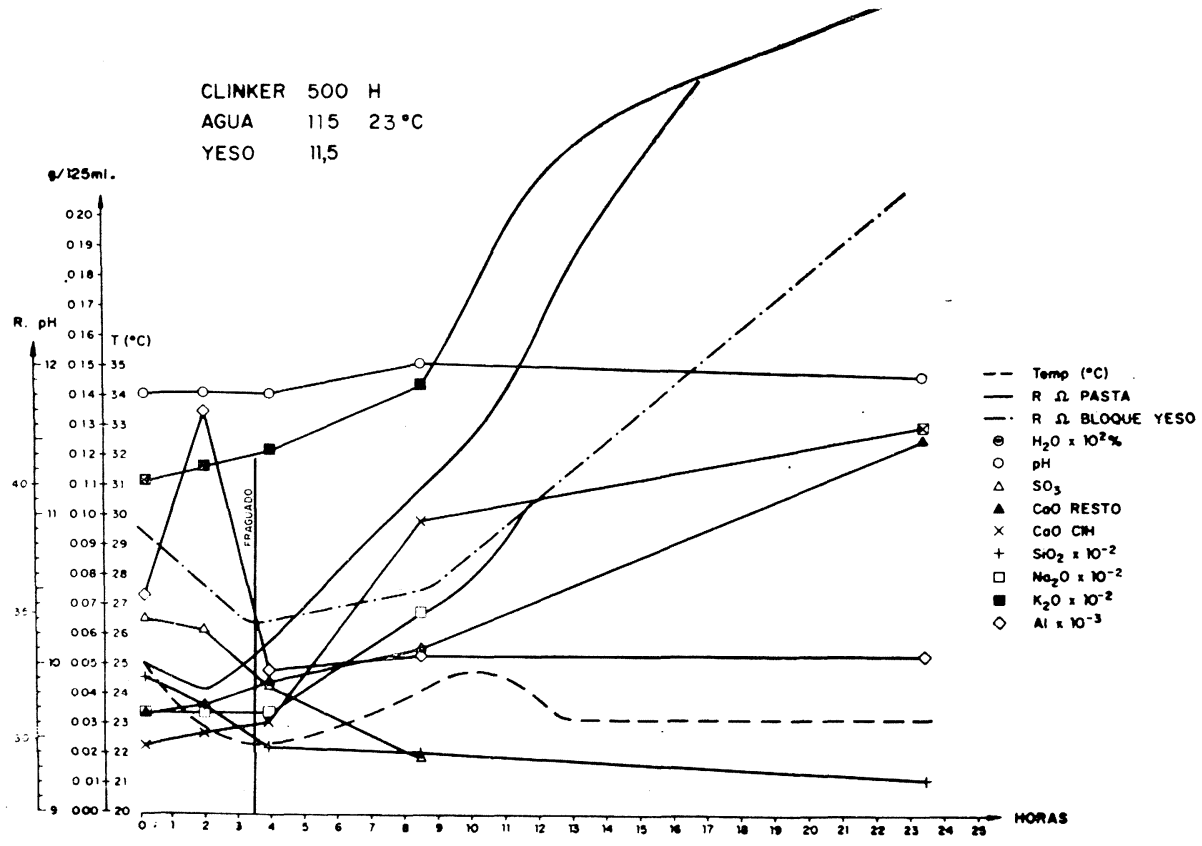

Fig. 9

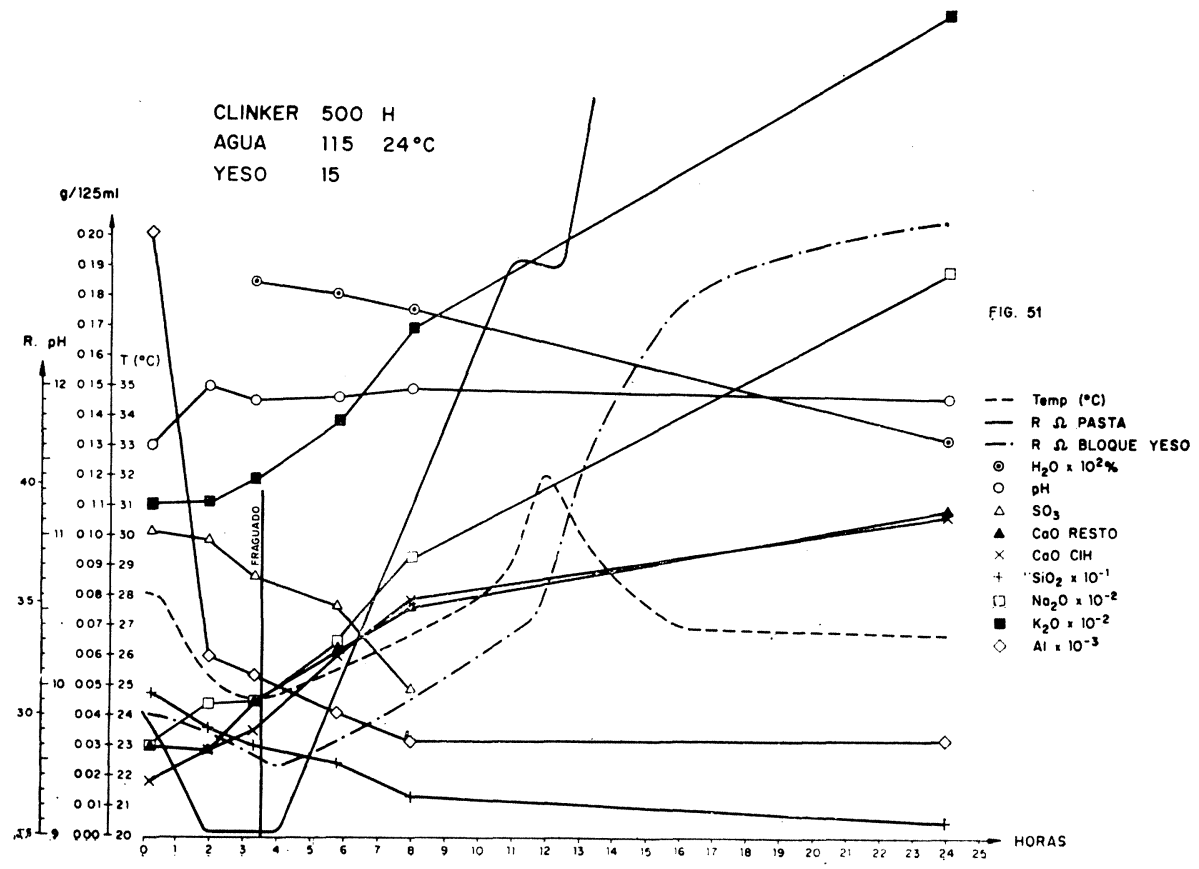

Fig. 10

Las siguientes figuras: 8, 9, 10 y 11, muestran que, al aumentar la proporción de yeso en la pasta, la curva desciende durante más tiempo y hasta un punto, a partir del cual nuevamente asciende (con mayor pendiente al aumentar el yeso en la pasta) hasta otro 
punto (más tardío cuanto más yeso tenga la pasta), a partir del cual hay un nuevo aumento de pendiente en la curva. El tiempo transcurrido entre los dos cambios de pendiente coincide con el comúnmente llamado "período durmiente de la pasta". Una curvatura suave indica pequeña velocidad de reacción; una recta paralela al eje de abscisas, que la velocidad de hidratación es nula; una disminución de la pendiente, que se produce una exudación de agua en la pasta, y un aumento de pendiente, que la pasta solicita agua para su hidratación.

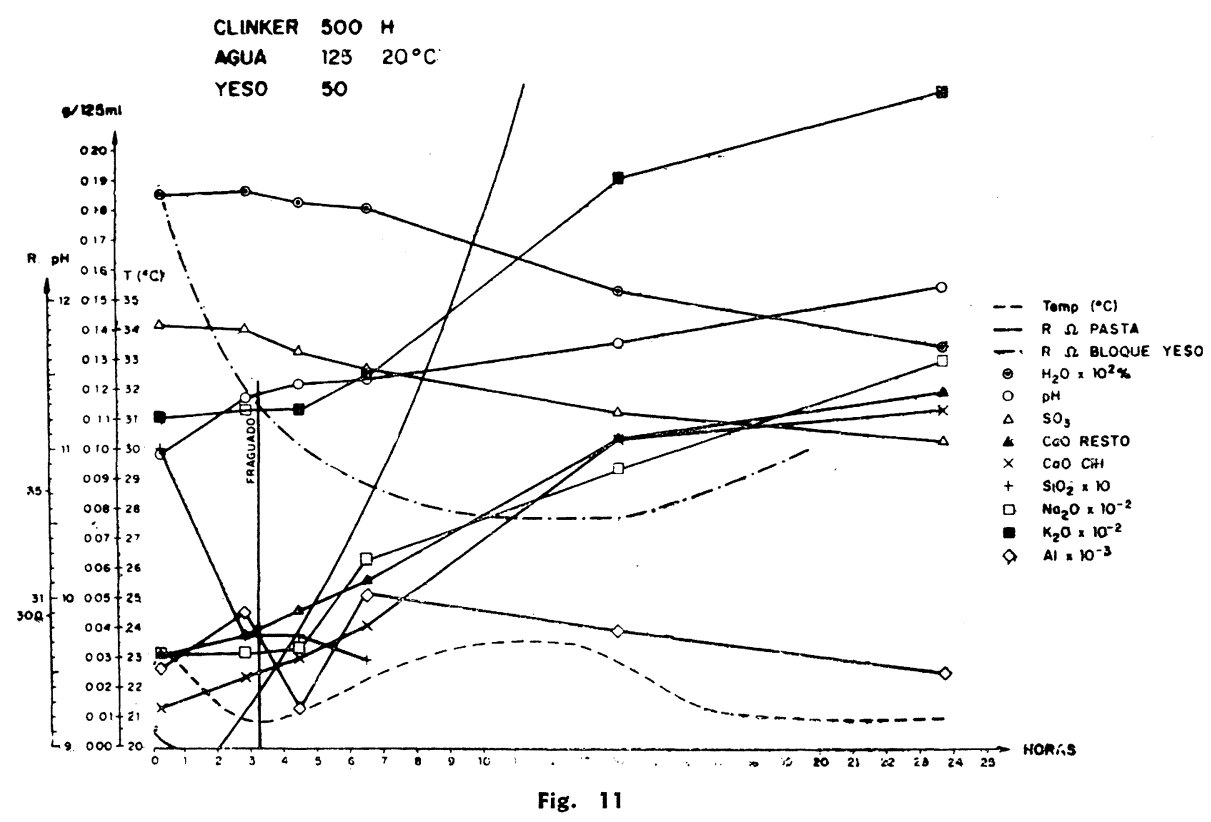

\subsubsection{Alcalis solubles}

2.1.2.1. Clínker, $500 \mathrm{~g}$; yeso, $0 \mathrm{~g}$; agua, $125 \mathrm{~g}$; T. a. $=20^{\circ} \mathrm{C}$ (fig. 7)

EI contenido de álcalis que pasan a disolución en $125 \mathrm{ml}$, expresados en forma de $\mathrm{Na}_{2} \mathrm{O}$ y $\mathrm{K}_{2} \mathrm{O}$, se mantiene constante durante las 11 primeras horas de la hidratación, siendo, respectivamente, del orden de $0,0007 \mathrm{~g} / 125 \mathrm{ml}$ y de $0,0019 \mathrm{~g} / 125 \mathrm{ml}$; a las 24 horas, el $\mathrm{Na}_{2} \mathrm{O}$ manifiesta una subida a $0,0016 \mathrm{~g} / 125 \mathrm{ml}$ y el $\mathrm{K}_{2} \mathrm{O}$ asciende a $0,0028 \mathrm{~g} / 125 \mathrm{ml}$. Las cantidades iniciales de álcalis extraídos son las mayores que se consiguieron.

En la muestra de pasta de $10 \mathrm{~g}$ hay $8 \mathrm{~g}$ del clínker $\mathrm{H}$ que contiene $0,0056 \mathrm{~g}$ de $\mathrm{Na}_{2} \mathrm{O}$ y $0,0152 \mathrm{~g}$ de $\mathrm{K}_{2} \mathrm{O}$ (cuadro II), potencialmente solubles. De las cantidades inicialmente extraídas: $0,0007 \mathrm{~g} / 125 \mathrm{ml}$ de $\mathrm{Na}_{2} \mathrm{O}$ y $0,0019 \mathrm{~g} / 125 \mathrm{ml}$ de $\mathrm{K}_{2} \mathrm{O}$, se deduce que hubo una solubilización inicial del 12,5\% de álcalis; posteriormente, hasta las 24 horas se solubilizaron, además, el $16 \%$ de $\mathrm{Na}_{2} \mathrm{O}$ y el $6 \%$ de $\mathrm{K}_{2} \mathrm{O}$ que existía en el clínker.

\subsubsection{Clínker, $500 \mathrm{~g}$; yeso, $7,5 \mathrm{~g}$; agua, $125 \mathrm{~g} ; \mathrm{T}$. a. $=24^{\circ} \mathrm{C}$ (fig. 12)}

Al desaparecer el $\mathrm{SO}_{3}$ soluble en el agua de extracción de la pasta se manifiesta un aumento brusco en la cantidad extraída de álcalis durante el segundo ciclo térmico ; mientras el $\mathrm{Na}_{2} \mathrm{O}$ sube de $0,00045 \mathrm{~g} / 125 \mathrm{ml}$ a $0,00067 \mathrm{~g} / 125 \mathrm{ml}$, con una solubilización del $4 \%$ del contenido del clínker, el $\mathrm{K}_{2} \mathrm{O}$ sube de 0,0014 a $0,0018 \mathrm{~g} / 125 \mathrm{ml}$, lo cual supone la solubilización del 2,6 \% del $\mathrm{K}_{2} \mathrm{O}$ del clínker. 
El aumento en la concentración de álcalis solubles coincide con un aumento de la conductividad, que se manifiesta por un mínimo en las curvas $R c-t$ y $R$ - $t$ (figura 2).

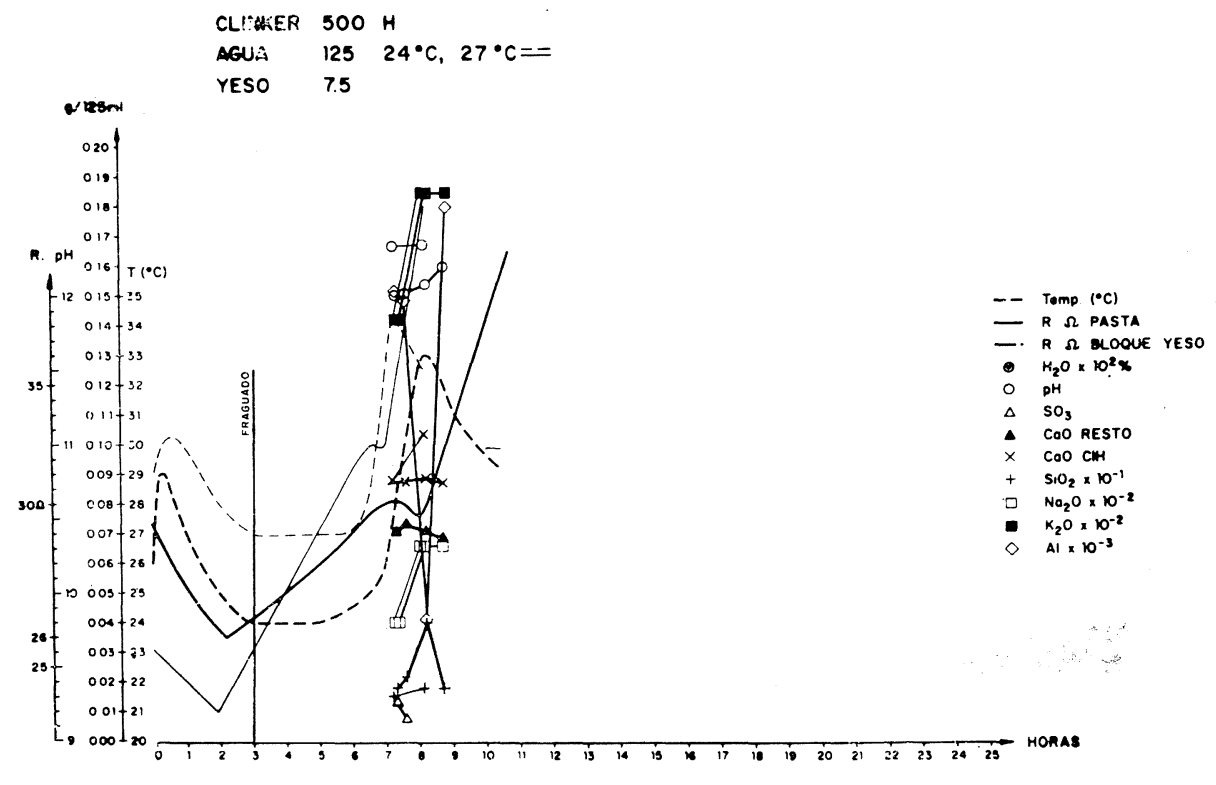

Fig. 12

2.1.2.3. Clínker, $500 \mathrm{~g}$; yeso, $10 \mathrm{~g}$; agua, $115 \mathrm{~g}$; T. a. $=20^{\circ} \mathrm{C}$ (fig. 8)

Aintes del segundo ciclo térmico, los contenidos de álcalis son del orden de 0,00042 g/125 $\mathrm{ml}$ de $\mathrm{Na}_{2} \mathrm{O}$ y de $0,0011 \mathrm{~g} / 125 \mathrm{ml}$ de $\mathrm{K}_{2} \mathrm{O}$; al desaparecer el $\mathrm{SO}_{3}$ soluble en el agua de extracción de la pasta, mientras el $\mathrm{Na}_{2} \mathrm{O}$ sube a $0,001130 \mathrm{~g} / 125 \mathrm{ml}$, lo cual indica un $16 \%$ de solubilización del contenido total del clínker, el $\mathrm{K}_{2} \mathrm{O}$ sube a $0,0026 \mathrm{~g} / 125 \mathrm{ml}$, lo cual supone la solubilización de un $10 \%$ del $\mathrm{K}_{2} \mathrm{O}$ del clínker.

El aumento en la concentración de álcalis coincide con un cambio de pendiente en la curva $R c-t$.

\subsubsection{Clínker, $500 \mathrm{~g}$; yeso, $11,5 \mathrm{~g}$; agua, $115 \mathrm{~g}$; T. a. $=23^{\circ} \mathrm{C}$ (fig. 9 )}

El aumento de temperatura ambiente ocasiona una aceleración de las reacciones de los aluminatos, de forma que el aumento en $\mathrm{Na}_{2} \mathrm{O}$ es perceptible; antes de comenzar el segundo ciclo térmico el aumento de álcalis se hace mayor, de forma que a las 24 horas el contenido de óxido sódico es cuatro veces el inicial y unas tres veces el potásico. La aparición de un mínimo en la curva $R c-t$ demuestra la influencia de los álcalis en la conductividad de la pasta.

\subsubsection{Clínker, $500 \mathrm{~g}$; yeso, $15 \mathrm{~g}$; agua, $115 \mathrm{~g}$; T. a. $=24^{\circ} \mathrm{C}$ (fig. 10)}

El pequeño aumento en la cantidad de yeso no es suficiente para compensar el ligero aumento de temperatura ambiente y disminuir la velocidad de hidratación de los aluminatos, por lo cual los resultados obtenidos son similares a los del caso anterior. En este caso el mínimo en las curvas $R c-t$ y $R$ - $t$ es claramente observable y perfectamente definido. 


\subsubsection{Clínker, $500 \mathrm{~g}$; yeso, $50 \mathrm{~g}$; agua, $125 \mathrm{~g}$; T. a. $=20^{\circ} \mathrm{C}$ (fig. 11)}

El contenido en $\mathrm{K}_{2} \mathrm{O}$ inicial y final es el menor de todos los casos; desde las 4 horas de hidratación, el óxido sódico se solubiliza progresivamente y las concentraciones finales no difieren mucho de las de los casos anteriores; el aumento en sodio se manifiesta después del fraguado de la pasta, y el que aumente progresivamente (habiendo $\mathrm{SO}_{3}$ abundante en la fase líquida) no tiene nada de particular, ya que se producen sulfoaluminatos durante un tiempo mayor y éstos eliminan el sodio por no admitirlo en su estructura cristalina. La fuerte concentración de $\mathrm{SO}_{3}$ hace que la velocidad de formación de sulfoaluminatos sea menor que en los casos anteriores, y, por lo tanto, también lo será la concentración de álcalis en la fase líquida. Ya que a las 24 horas todavía queda yeso y, por lo tanto, $\mathrm{SO}_{3}$ en la fase líquida, no podrá producirse el segundo ciclo térmico, y cuando se produzca - debido a la hidratación del aluminato tricálcico restante-, como sucedió en los casos anteriores (excepto en el primero), tendrá valores térmicos poco elevados; en estos casos en que el ciclo térmico, debido a los aluminatos, tarda en producirse puede manifestarse un segundo ciclo térmico - también con temperaturas poco elevadas-, ocasionado por la hidratación de la alita y la cristalización del hidróxido cálcico resultante.

\subsubsection{Agua no combinada}

Durante las primeras 24 horas de hidratación de la pasta, cuando la temperatura ambiente es de unos $20^{\circ} \mathrm{C}$, el agua no combinada, determinada por el método indicado en el punto 1.3.4., disminuye un $30 \%$; si la temperatura ambiente aumenta $\left(24^{\circ} \mathrm{C}\right)$, el agua no combinada disminuye un $40 \%$.

La disminución del agua no combinada - tomada por la pasta al hidratarse- comienza a las 2-3 horas de iniciarse la prueba y es perceptible al comenzar el fin del fraguado.

\subsection{4. $\mathrm{CaO}$ restante; alcalinidad total}

El hidróxido cálcico producido en la hidratación se expresa como "CaO restante" y resulta de descontar al $\mathrm{CaO}$ total encontrado en los $125 \mathrm{ml}$ de agua de extracción el $\mathrm{CaO}$ correspondiente al sulfato cálcico (yeso soluble) encontrado en los $125 \mathrm{ml}$ de agua de extracción.

La disolución contiene inicialmente mayor cantidad de $\mathrm{CaO}$ restante cuando la pasta no tiene yeso y aumenta la solubilidad de $\mathrm{CaO}$ restante al hacerlo la proporción de yeso añadido; a las 24 horas las concentraciones de $\mathrm{CaO}$ restante son parecidas en todos los casos.

La temperatura ambiente (T. a.) influye en la concentración de $\mathrm{CaO}$ restante, aumentando su concentración al hacerlo la temperatura.

La concentración de $\mathrm{CaO}$ restante tiende a aumentar en el entorno del fin del fraguado, medido con la aguja de Vicat, y manifiesta un ligero aumento en el segundo máximo térmico.

La alcalinidad total se obtuvo por neutralización y es de un orden semejante al del $\mathrm{CaO}$ restante; la concentración de $\mathrm{CaO}$ obtenida por neutralización con $\mathrm{ClH}$ también nos da, por otro método, la cantidad de hidróxido cálcico producido durante la hidratación, más, como en el caso de tener la fase líquida otros hidróxidos, como pueden ser los alcalinos, la denominamos alcalinidad total. La alcalinidad total es máxima inicialmente cuando la muestra no contiene yeso y tiende a aumentar, con valores menores, para muestras con contenidos crecientes de yeso. La alcalinidad total final tiende a aumentar para muestras con contenidos crecientes de yeso. 
En el siguiente cuadro se pueden comparar los valores obtenidos:

Resultados obtenidos por extracción en $125 \mathrm{ml}$ de agua de muestras de pastas de $10 \mathrm{~g}$

\begin{tabular}{|c|c|c|c|c|c|c|}
\hline \multirow{2}{*}{\multicolumn{2}{|c|}{$\begin{array}{l}\text { Contenido de } \\
\text { yeso de la } \\
\text { muestra en } \mathrm{g}\end{array}$}} & \multirow{2}{*}{$\mathrm{SO}_{3}$ inicial } & \multicolumn{2}{|c|}{$\mathrm{CaO}$ restante } & \multicolumn{2}{|c|}{ Alcalinidad total } \\
\hline & & & Inicial & Final & Inicial & Final \\
\hline 0 & $\begin{array}{lllll}\ldots & \ldots & \ldots & \ldots & \ldots\end{array}$ & 0,0000 & 0,0454 & 0,1055 & 0,0350 & 0,0960 \\
\hline 10 & $\begin{array}{lllll}\ldots & \ldots & \ldots & \ldots & \ldots\end{array}$ & 0,0553 & 0,0228 & 0,1032 & 0,0169 & 0,1047 \\
\hline 15 & $\begin{array}{lllll}\ldots & \ldots & \ldots & \ldots & \ldots\end{array}$ & 0,1010 & 0,0293 & 0,1099 & 0,0183 & 0,1067 \\
\hline 50 & $\begin{array}{lllll}\ldots & \ldots & \ldots & \ldots & \ldots\end{array}$ & 0,1447 & 0,0314 & 0,1176 & 0,0122 & 0,1123 \\
\hline
\end{tabular}

El pH del extracto acuoso aumenta durante las primeras horas de hidratación, se estabiliza en valores próximos a 12 y no varía significativamente durante el resto de la hidratación. La temperatura del ambiente provoca valores de $\mathrm{pH}$ más elevados conseguidos más rápidamente.

\subsubsection{Hierro y alúmina solubles}

No se detectó hierro soluble analíticamente. La cantidad de aluminio soluble no se detectaba con amoníaco; se efectuó la determinación de la alúmina colorimétricamente con aluminón. Se observó que la concentración de aluminio alcanzaba un máximo, dentro de las 3 primeras horas de la hidratación, que coincidía con un aumento en la conductividad de la pasta (figs. 7 a 12) y descendía hasta las 4-8 horas a partir del máximo. Posteriormente, para contenidos altos de yeso $(50 \mathrm{~g})$, la concentración de aluminio aumenta unas 2 horas, y seguidamente desciende hasta las 24 horas; para contenidos intermedios de yeso (11,5-15 g), la concentración en aluminio se mantiene hasta las 24 horas; para contenidos más bajos de yeso ( $10 \mathrm{~g})$, el aluminio soluble tiende a aumentar hasta las 24 horas, y cuando la pasta no contiene yeso, la concentración de aluminio aumenta rápidamente hasta las 24 horas.

\subsubsection{Sílice soluble}

La solubilidad de la sílice determinada colorimétricamente es máxima al iniciarse la hidratación y tiende a disminuir al aumentar el tiempo de hidratación de la pasta. Coincidiendo con el segundo máximo térmico hay un aumento de concentración en la sílice.

\subsection{8. $\mathrm{SO}_{3}$ soluble.}

En las condiciones de preparación de la muestra de $125 \mathrm{ml}$ empleadas por nosotros, la concentración de $\mathrm{SO}_{3}$ soluble decrece linealmente.

La pendiente de la línea que indica la concentración de $\mathrm{SO}_{3}$ soluble es mayor para contenidos decrecientes de yeso en la pasta.

Al aumentar la temperatura ambiente aumenta la solubilidad del $\mathrm{SO}_{3}$.

\subsection{Resultados de la hidratación con el clínker I}

Vienen dados en el cuadro III y representados en las figuras 16, 17 y 18. Todos los ensayos se han realizado con una temperatura ambiente de $22^{\circ} \mathrm{C}$. 


\subsubsection{Clínker, $500 \mathrm{~g}$; yeso, 0 ; agua, $125 \mathrm{~g}$}

Máximo de $29^{\circ} \mathrm{C}$ a los $10 \mathrm{~min}$, y segundo ciclo térmico con un máximo de $27^{\circ} \mathrm{C}$ a las 13 horas del comienzo de la prueba. Los valores de temperaturas son más altos que los del clínker $\mathrm{H}$.

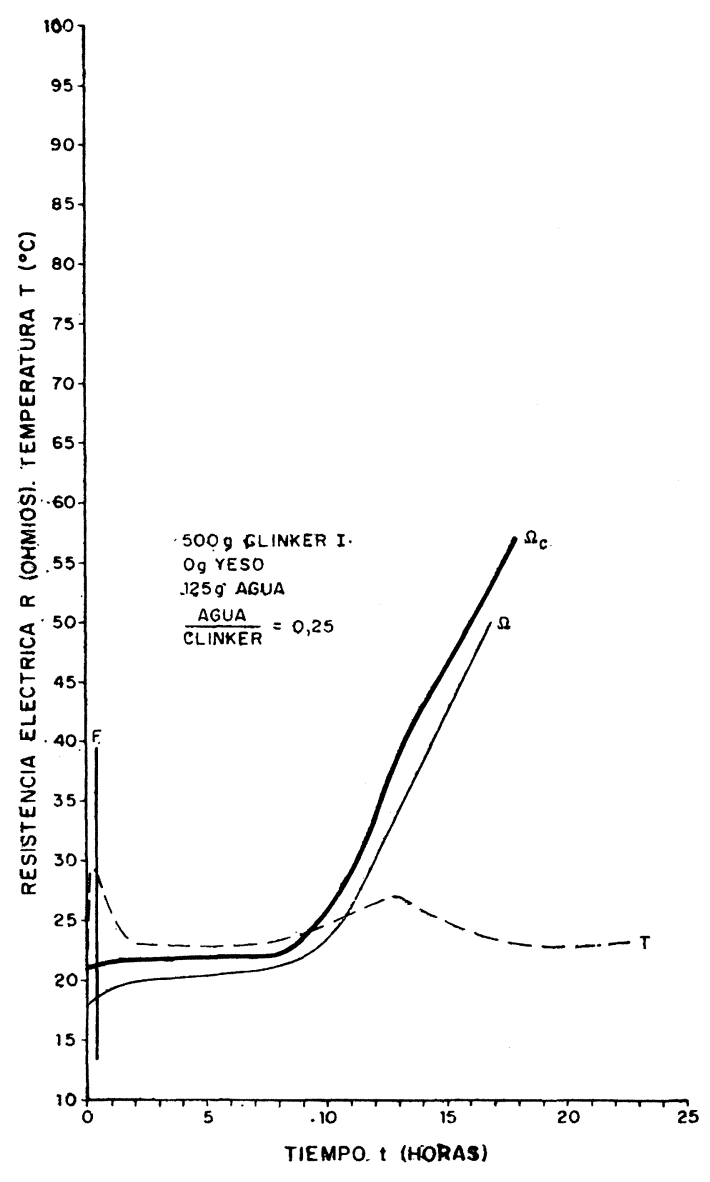

Fig. 13

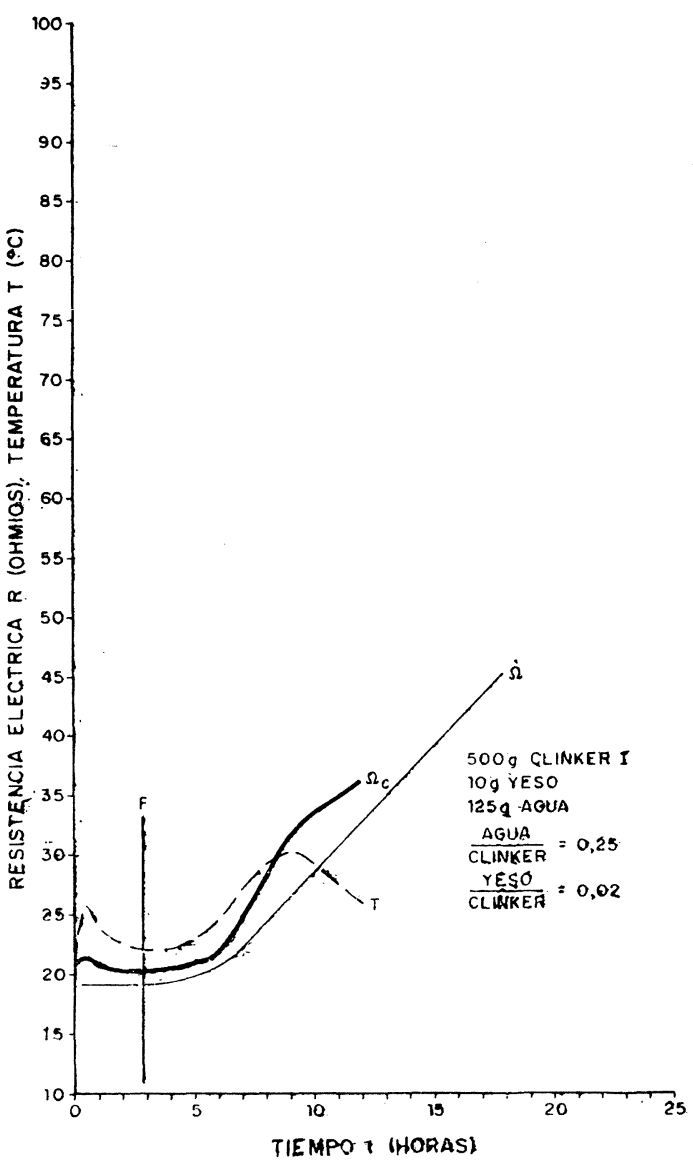

Fig. 14

La resistencia eléctrica corregida se estabiliza en 21 ohmios durante las primeras 8 horas; al iniciarse el segundo ciclo térmico crece progresivamente, percibiéndose un ligero cambio a las 13 horas, a partir de las cuales asciende continuamente.

\subsubsection{Clínker, $500 \mathrm{~g}$; yeso, $10 \mathrm{~g}$; agua, $125 \mathrm{~g}$}

Primer ciclo térmico, con un máximo de $25^{\circ} \mathrm{C}$, y comienzo del segundo ciclo térmico, coincidente con el fin del fraguado, con un máximo de $30^{\circ} \mathrm{C}$ a las 9 horas.

La resistencia eléctrica corregida se estabiliza en 21 ohmios durante unas 5 horas; después crece progresivamente a partir de las 6 horas, coincidiendo con el comienzo del segundo ciclo térmico, cuyo máximo de temperatura señala un cambio de curvatura, correspondiente a una menor pendiente en la curva. 
La resistencia eléctrica sin corregir, en cambio, no acusa este cambio de curvatura y es lineal su subida a partir del inicio del segundo ciclo térmico.

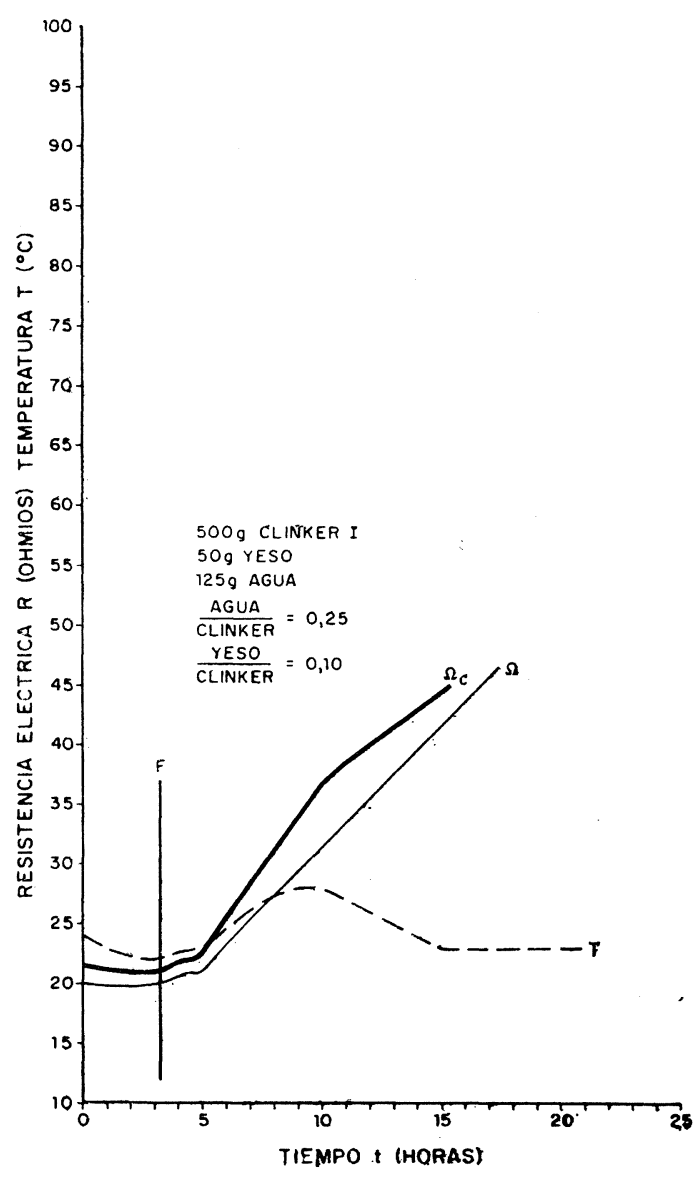

Fig. 15

\author{
2.2.1.3. Clínker, $500 \mathrm{~g}$; yeso, $50 \mathrm{~g}$; \\ agua, $125 \mathrm{~g}$
}

Primer ciclo, térmico con un máximo de $24^{\circ} \mathrm{C}$ a los $10 \mathrm{~min}$; segundo ciclo térmico con un máximo de $27^{\circ} \mathrm{C}$ a las 9 horas; el fin del fraguado coincide con el principio del segundo ciclo térmico.

La resistencia eléctrica corregida se estabiliza en 22 ohmios durante unas 3 horas; a las 5 horas comienza a aumentar su pendiente hasta las 10 horas, en donde disminuye.

La curva de las resistencias eléctricas sin corregir sube linealmente con pendiente constante a partir de las 5 horas.

\subsubsection{Medidas de humedad con el bloque de yeso}

2.2.2.1. Clínker, $500 \mathrm{~g}$; yeso, $0 \mathrm{~g}$; agua, $125 \mathrm{~g}$

La curva que representa el intercambio de agua que sufre el bloque de yeso con la pasta comienza con una rama parabólica asintótica al eje de ordenadas; hacia las 2 horas toma curvatura y se hace paralela al eje de abscisas, a las 8 horas. A partir de entoces se equilibra el agua de la pasta con la del bloque de yeso hasta las 13 horas, donde comienza la subida, debido a una disminución de agua en el bloque, solicitada por la pasta al hidratarse, y que coincide con el máximo del segundo ciclo térmico.

\subsubsection{Clínker, $500 \mathrm{~g}$; yeso, $10 \mathrm{~g}$; agua, $125 \mathrm{~g}$}

La curva desciende hasta el fin del fraguado, que también coincide con el comienzo del segundo ciclo térmico, a las 2 horas y $40 \mathrm{~min}$; a partir de entonces sube casi simétricamente al descenso anterior.

\subsubsection{Clínker, $500 \mathrm{~g}$; yeso, $50 \mathrm{~g}$; agua, $125 \mathrm{~g}$}

La curva representativa del intercambio del agua tiene la forma típica de una parábola simétrica con características similares a las del caso anterior. Hay que indicar que los valores de la resistencia de estas curvas son menores al aumentar la cantidad de yeso que contiene la pasta.

Las dos últimas pastas, por la forma de las gráficas de las resistencias eléctricas del bloque de yeso, manifiestan una mayor velocidad de hidratación. 


\subsubsection{Fraguados medidos con la aguja de Vicat}

Los finales de fraguado coinciden en los tres casos con un aumento de temperatura: en el primer caso dentro del primer ciclo térmico y en los dos siguientes con el comienzo del segundo ciclo térmico. Los resultados vienen a continuación:

\begin{tabular}{cccccc}
\hline Clinker & Yeso & Agua & Figuras & \multicolumn{2}{c}{ Fin del fraguado } \\
\cline { 4 - 5 }$(\mathbf{g})$ & $\mathbf{( g )}$ & $\mathbf{( g )}$ & (núm.) & (horas) & (min) \\
\hline 500 & 0 & 125 & $13-16$ & 0 & 15 \\
500 & 10 & 125 & $14-17$ & 2 & 40 \\
500 & 50 & 125 & $15-18$ & 3 & 10 \\
\hline
\end{tabular}

\subsubsection{Alcalis solubles}

El contenido en álcalis solubles del clínker I es mayor que el del clínker $\mathrm{H}$ estudiado anteriormente.

Los álcalis del clínker I se encuentran en su mayor parte en forma de sulfatos alcalinos fácilmente solubles; por dicha causa, las variaciones de concentración de álcalis en la fase líquida durante la hidratación son mínimas, como pone de relieve el cuadro III, a diferencia del cuadro II.

\subsection{5. $\mathrm{CaO}$ restante; alcalinidad total}

El $\mathrm{CaO}$ restante aumenta a partir del fin del fraguado; este aumento prosigue después más lentamente y de modo casi lineal, coincidiendo con la subida final de la curva $R$ - $t$ y con el segundo ciclo térmico.

Las concentraciones a las 24 horas disminuyen al aumentar la cantidad de yeso que contiene el cemento de partida.

Los valores de $\mathrm{CaO}$ obtenidos por neutralización con $\mathrm{ClH}$, que denominamos alcalinidad total, son mayores que los de $\mathrm{CaO}$ restante por influir la cantidad de álcalis en dicha neutralización.

\subsubsection{Hierro y alúmina solubles}

No se detectó hierro en las disoluciones. La concentración de aluminio disuelto alcanza una concentración de $0,11 \times 10^{-3} \mathrm{~g} / 125 \mathrm{ml}$ en las primeras horas de hidratación. Al disminuir la concentración de $\mathrm{SO}_{3}$ en los $125 \mathrm{ml}$ (al efectuar extracciones a tiempos mayores de hidratación), también lo hace la concentración de aluminio; si la concentración de $\mathrm{SO}_{3}$ a las 24 horas de hidratación aún es alta (50 g de yeso), la concentración de aluminio soluble se hace despreciable analíticamente; si la concentración de $\mathrm{SO}_{3}$ disminuye rápidamente en los extractos acuosos (concentraciones del orden del $0,05 \mathrm{~g} / 125 \mathrm{ml}, 0 \mathrm{~g}$ de yeso), el contenido de aluminio soluble se eleva de nuevo a valores similares a los iniciales.

\subsection{7. $\mathrm{SO}_{3}$ soluble}

Las concentraciones de $\mathrm{SO}_{3}$ soluble son en este caso mayores que en el del clínker anteriormente estudiado, ya que el clínker I tiene $\mathrm{SO}_{3}$; la velocidad de desaparición del $\mathrm{SO}_{3}$ soluble es, por lo tanto, menor en el caso presente. 


\subsection{Cemento D (cuadro III, figs. 19 y 20); T. a. $=20^{\circ} \mathrm{C}$}

\subsubsection{Curvas térmicas y de resistencia eléctrica}

La línea que representa las temperaturas presenta dos máximos: el primero de $24^{\circ} \mathrm{C}$ a los $30 \mathrm{~min}$ y el segundo de $23^{\circ} \mathrm{C}$ a las 10 horas.

La línea que representa la resistencia eléctrica corregida tiene inicialmente un descenso de 40 a 30 ohmios durante la primera hora y media; luego la resistencia de la pasta asciende hasta 38 ohmios a las 7 horas; vuelve a descender de nuevo hasta 34 ohmios a las 9 horas, y a partir de entonces la subida de la resistencia es continua.

La curva de las resistencias eléctricas sin corregir $(R-t)$ tiene características similares a la corregida $(R c-t)$, ya que la influencia de la temperatura fue mínima sobre las variaciones de la conductividad.

\subsubsection{Agua no combinada}

El agua no combinada disminuyó desde un $19 \%$ al comienzo de la hidratación hasta un $11 \%$ a las 24 horas.

\subsubsection{Fraguado medido con la aguja Vicat}

El fin del fraguado se dio a las 3 horas y $30 \mathrm{~min}$, coincidiendo con el comienzo del segundo ciclo térmico.

\subsubsection{Alcalis solubles}

En el cuadro III se puede apreciar que el contenido de álcalis del clínker D es intermedio entre los $\mathrm{H}$ e I. $\mathrm{El}$ análisis del $\mathrm{SO}_{3}$ del clínker demuestra que aunque parte de los álcalis de este clínker se encuentran en forma de sulfatos, existen también combinados con el aluminato tricálcico en forma de óxidos. Los álcalis aumentan rápidamente durante la primera hora, tienen un segundo aumento hacia las 9 horas y posteriormente se estabilizan.

\subsection{5. $\mathrm{CaO}$ restante; alcalinidad total}

El elevado contenido de cal libre de este cemento da lugar a una concentración inicial de hidróxido cálcico muy elevada, la cual aumenta hasta las 6 horas, desciende después hasta las 8 horas (coincidiendo con un aumento en la conductividad eléctrica) y se estabiliza después.

\subsubsection{Alúmina soluble}

La concentración inicial de aluminio soluble desciende hasta las 6 horas y cuando desaparece el $\mathrm{SO}_{3}$ de la fase líquida vuelve de nuevo a aumentar la concentración del aluminio.

\subsection{7. $\mathrm{SO}_{3}$ soluble}

$\mathrm{El} \mathrm{SO}_{3}$ soluble disminuye linealmente, en las condiciones empleadas en nuestro caso, hasta las 9 horas momento en el que no se detecta $\mathrm{SO}_{3}$ en la fase líquida. 


\section{INTERPRETACION}

\subsection{Hidratación del Clínker $H$ con distintas cantidades de yeso}

\subsubsection{Clínker $\mathrm{H}$ con $0 \mathrm{~g}$ de yeso (fig. 1)}

En el caso de la hidratación del clínker sin yeso, las curvas térmicas, de conductividad de la pasta, de humedad del bloque de yeso y de contenido de agua de la pasta inician una hidratación progresiva, aunque lenta, dadas sus pequeñas pendientes. El agua comienza a combinarse desde las 2 primeras horas y no es rechazada de la mezcla en forma de segregación, rezumado o exudación, como sucede en los casos en que al clínker se le añade yeso.

La rápida disolución de la cal de hidrólisis de los silicatos hace que se retrase el fraguado con la aguja de Vicat y que disminuya la concentración de aluminatos, inicialmente presentes en disolución, por insolubilización de los compuestos hidratados correspondientes. El contenido en álcalis solubles confirma lo dicho antes, ya que la concentración del sodio prácticamente no aumenta durante la hidratación, lo cual hace suponer que el compuesto sódico del aluminato tricálcico se hidrata inicialmente, desprendiendo el álcali y provocando un primer ciclo térmico. Esta confirmación es válida, por cuanto que el clínker $\mathrm{H}$ no contiene en absoluto sulfatos (cuadro IV), por lo cual los álcalis -escasos, por supuesto- no pueden encontrarse en forma de sulfatos, sino combinados con silicatos y aluminatos en la forma habitual.

La insolubilización de los aluminatos contribuye a la rigidez inicial, coincidente con el final del fraguado, perceptible por la aguja de Vicat.

El proceso de la hidratación de la alita se puede seguir a partir de las 3 horas por los aumentos de $\mathrm{CaO}$ y $\mathrm{SiO}_{2}$ solubles (fig. 7); hacia las 6 horas aumenta la velocidad de hidratación de la alita y se inicia el segundo ciclo térmico con un máximo a las 11 horas; se hace visible entonces por difracción de rayos $\mathrm{X}$ (fig. 21) el hidróxido cálcico, que cristaliza. El proceso en conjunto es exotérmico, y a ello contribuye también la hidratación del $\mathrm{C}_{3} \mathrm{~A}$, ya que aparecen álcalis solubles, y particularmente sodio.

El aumento de potasio se debe al combinado en forma de $\mathrm{KC}_{8} \mathrm{~A}_{3}$, y no creemos pertenezca a otras fases del clínker, ya que la belita y el ferrito aluminato tetracálcico (fig. 22), poco cristalizados y más inertes, no se hidratan, según muestran las gráficas (figs. 21 y 24), y permanecen inalterados a las 11 horas. Durante las 6 primeras horas no hay aumentos sustanciales de álcalis, y en los difractogramas (figs. 21 y 23 ) solamente se observa la disminución de la alita, lo cual es una prueba de que los álcalis no pertenecen a la fase alítica. Otra prueba de lo mismo es que a las 11 horas (figs. 21 y 23) disminuye el aluminato tricálcico y entonces aumentan paralelamente los álcalis solubles, lo cual demuestra que tanto el sodio como el potasio están combinados con el aluminato tricálcico.

\subsubsection{Clínker $\mathrm{H}$ con $7,5 \mathrm{~g}$ de yeso}

En las curvas $R$-t y $R c$ - $t$ (fig. 2) aparecen dos mínimos, o por lo menos uno y un cambio de pendiente; la aparición de dos ciclos térmicos relacionados con los cambios de resistencia podrían hacer pensar en su influencia en la formación de los mínimos de resistencia eléctrica, más al efectuar la corrección de la resistencia en función de las temperaturas, persisten dichos mínimos, lo cual demuestra que no se deben a un efecto térmico.

Coincide el aumento brusco de álcalis solubles (fig. 12) con la aparición del segundo mínimo y con la desaparición del $\mathrm{SO}_{3}$ soluble; se interpreta esto como el fin de la formación de ettringita, y por la misma razón también se hidratan las demás fases, principalmente el aluminato tricálcico. 
El aumento de la velocidad de hidratación de la alita es favorecido por la cristalización exotérmica del hidróxido cálcico que se elimina de la disolución y que es perceptible por difracción de rayos X (fig. 21). La sílice soluble suministrada por la alita aumenta temporalmente (fig. 12) en la disolución, como pone de relieve el análisis de la fase líquida (cuadro II).

Al desaparecer de la disolución el $\mathrm{SO}_{3}$ soluble, según se vio anteriormente, aumenta el contenido de álcalis solubles y disminuye el contenido de aluminio soluble; la explicación es la siguiente: los álcalis se encuentran en forma de sulfatos alcalinos, ya que los hidróxidos que provienen de la hidrólisis de los aluminatos que los contienen están totalmente disociados, según [a]:

$$
\begin{aligned}
6 \mathrm{NaOH} & \rightarrow 6 \mathrm{Na}^{+}+6 \mathrm{OH}^{-} \\
6 \mathrm{KOH} & \rightarrow 6 \mathrm{~K}^{+}+6 \mathrm{OH}^{-}
\end{aligned}
$$

Pero en la disolución existen también yeso e hidróxido cálcico parcialmente disociados según $[\mathrm{b}]$ y $[\mathrm{c}]$, respectivamente:

$$
\begin{aligned}
3 \mathrm{CaSO} & \rightarrow 3 \mathrm{Ca}^{++}+3 \mathrm{SO}^{=} \\
3 \mathrm{Ca}(\mathrm{OH})_{2} & \rightarrow 3 \mathrm{Ca}^{++}+3 \mathrm{OH}^{-}
\end{aligned}
$$

los cuales, por el catión común $\mathrm{Ca}^{++}$, puede admitirse que dan lugar al nuevo equilibrio [d]:

$$
3 \mathrm{CaSO}_{4}+6 \mathrm{OH}^{-} \rightarrow 3 \mathrm{Ca}(\mathrm{OH})_{2}+3 \mathrm{SO}_{4}=
$$

Este estaría normalmente desplazado hacia la derecha, dada la menor solubilidad del hidróxido cálcico en relación con el sulfato cálcico.

Pero además, la mayor concentración de $\mathrm{OH}^{-}$causada por los álcalis según [a] es otra razón para el desplazamiento de [b] y [d] hacia la derecha, o de [c] hacia la izquierda. En suma, en la disolución se establece una mayor concentración de iones $\mathrm{SO}_{4}{ }^{=}$junto con los cationes alcalinos, de tal manera que se puede admitir la disociación [e]:

$$
\begin{aligned}
3 \mathrm{NaSO}_{4} & \rightarrow 6 \mathrm{Na}^{+}+3 \mathrm{SO}_{4}= \\
3 \mathrm{KSO}_{4} & \rightarrow 6 \mathrm{~K}^{+}+3 \mathrm{SO}_{4}=
\end{aligned}
$$

Entre [c] y [e] puede imaginarse, al menos desde un punto de vista formal, que en la fase líquida se establece el equilibrio [f], suma de los dos, y análogo, una vez más, al [d]:

$$
\begin{aligned}
& 3 \mathrm{CaSO}_{4}+6 \mathrm{NaOH} \rightarrow 3 \mathrm{Ca}(\mathrm{OH})_{2}+3 \mathrm{Na}_{2} \mathrm{SO}_{4} \\
& 3 \mathrm{CaSO}_{4}+6 \mathrm{KOH} \rightarrow 3 \mathrm{Ca}(\mathrm{OH})_{2}+3 \mathrm{~K}_{2} \mathrm{SO}_{4}
\end{aligned}
$$

y normalmente desplazado hacia la derecha. Ahora bien, el sulfato cálcico reacciona con el $\mathrm{C}_{3} \mathrm{~A}$ y agua para formar ettringita de forma irreversible según [g]:

$$
3 \mathrm{CaSO}_{4}+\mathrm{C}_{3} \mathrm{~A}+32 \mathrm{H}_{2} \mathrm{O} \rightarrow \mathrm{C}_{3} \mathrm{~A} \cdot 3 \mathrm{CaSO}_{4} \cdot 32 \mathrm{H}_{2} \mathrm{O}
$$

Como la ettringita es mucho menos soluble que el $\mathrm{CaSO}_{4}$ y que el $\mathrm{Ca}(\mathrm{OH})_{2}$, consume $\mathrm{CaSO}_{4}$, con el consiguiente desplazamiento de [d] o de [f] a la izquierda, lo cual quiere decir que los álcalis se encuentran al final de todo el proceso en forma de hidróxidos en la fase líquida, tal como también pone de relieve [h], suma de [f] y de [g].

$$
\begin{aligned}
& 3 \mathrm{Na}_{2} \mathrm{SO}_{4}+3 \mathrm{Ca}(\mathrm{OH})_{2}+\mathrm{C}_{3} \mathrm{~A}+32 \mathrm{H}_{2} \mathrm{O} \rightarrow 6 \mathrm{NaOH}+\mathrm{C}_{3} \mathrm{~A} \cdot 3 \mathrm{CaSO}_{4} \cdot 32 \mathrm{H}_{2} \mathrm{O} \\
& 3 \mathrm{~K}_{2} \mathrm{SO}_{4}+3 \mathrm{Ca}(\mathrm{OH})_{2}+\mathrm{C}_{3} \mathrm{~A}+32 \mathrm{H}_{2} \mathrm{O} \rightarrow 6 \mathrm{KOH}+\mathrm{C}_{3} \mathrm{~A} \cdot 3 \mathrm{CaSO}_{4} \cdot 32 \mathrm{H}_{2} \mathrm{O}
\end{aligned}
$$

Estos hidróxidos alcalinos, totalmente disociados, son la causa del aumento de la conductividad de la disolución, así como de la insolubilización del hidróxido cálcico por desplazamiento de [c] hacia la izquierda, lo cual provoca a su vez la consiguiente aceleración de la hidratación de la alita. 
La tendencia del aluminio soluble a aumentar a partir de este momento, y dada la insolubilidad de la ettringita, prueba la nueva hidratación del aluminato tricálcico, el cual forma monosulfoaluminatos por reacción con la ettringita, según [i]:

$$
2 \mathrm{C}_{3} \mathrm{~A}+\mathrm{C}_{3} \mathrm{~A} \cdot 3 \mathrm{CaSO}_{4} \cdot 32 \mathrm{H}_{2} \mathrm{O}+4 \mathrm{H}_{2} \mathrm{O} \rightarrow 3 \mathrm{C}_{3} \mathrm{~A} \cdot \mathrm{CaSO}_{4} \cdot 12 \mathrm{H}_{2} \mathrm{O}
$$

\subsubsection{Clínker $\mathrm{H}$ con $10 \mathrm{~g}$ de yeso}

Al comparar los resultados obtenidos en este caso con los del punto 3.1.1. vemos que la cantidad de yeso añadida origina notables cambios: hay un retraso en el fraguado medido con la aguja de Vicat y se producen dos ciclos térmicos, un mínimo y un cambio de pendiente en la curva de resistencia eléctrica (fig. 3) como en 3.1.2. El segundo mínimo no se aprecia con claridad en este caso. El yeso forma con el aluminato tricálcico ettringita lo suficientemente impermeable para impedir la hidratación de la alita y retrasar la hidratación de todas las fases en general. Al reaccionar el aluminato, los álcalis que contiene pasan a la fase líquida y parte del aluminato tricálcico también se solubiliza; esto provoca un aumento en el $\mathrm{pH}$ y de la conductividad de la pasta, lo cual se refleja en el primer mínimo de la curva de resistencia.

El agua de la pasta no reacciona instantáneamente, y esto se percibe en la curva de resistencia eléctrica del bloque de yeso (fig. 8). Hay un período de estabilidad, durante el cual continúan las reacciones anteriores hasta que todo el yeso se insolubiliza. Mientras tanto, la ettringita que se formó da una cierta trabazón a la pasta, junto con la tobermorita amorfa, que se insolubiliza, como muestra la curva de solubilidad del $\mathrm{SiO}_{2}$.

Agotado el yeso en la fase líquida, la ettringita precipitada reacciona con más aluminato tricálcico y se hace permeable, reaccionando a partir de entonces más rápidamente la alita. El hidróxido cálcico resultante no pasa a la fase líquida, sino que cristaliza por estar ésta más saturada, con lo cual se provoca una reacción exotérmica que acelera aún más la hidratación del aluminato tricálcico, lo cual se percibe por el aumento de la proporción de álcalis solubles en la fase líquida.

Todos los procesos descritos responden a los esquemas de reacciones expuestos en el punto 3.1.2., por lo que apenas existe diferencia entre lo que sucede con el clínker $\mathrm{H}$ adicionado de 7,5 g y $10 \mathrm{~g}$ de yeso en cada caso. Las diferencias que pueden apreciarse entre las figuras 8 y 12 se explican fácilmente por las distintas temperaturas a que se llevó en uno y otro caso la hidratación, más que a la diferente cantidad de yeso en ambos.

\subsubsection{Clínker $\mathrm{H}$ con $11,5 \mathrm{~g}$ de yeso}

Los fenómenos que suceden durante la hidratación son semejantes a los de los casos anteriores, aunque más atenuados, ya que al aumentar el yeso en la disolución se favorece la insolubilidad de la ettringita formada.

Se retrasa así la hidratación de la alita y la formación del segundo ciclo térmico consiguiente.

En este caso, el mínimo que se observa en la curva de resistencia eléctrica corregida (fig. 4) es ocasionado por la brusca solubilización de los álcalis.

La temperatura ambiente más elevada acelera, por otra parte, el fin del fraguado medido con la aguja de Vicat, que coincide en el tiempo con el del caso anterior.

\subsubsection{Clínker $\mathrm{H}$ con $15 \mathrm{~g}$ de yeso}

El aumento de la proporción de yeso, junto con el aumento en la temperatura ambiente, hace que la pendiente de la curva $R c$ - $t$ sea mayor. Un segundo ciclo térmico con temperaturas más elevadas acelera las reacciones de hidratación y de nuevo se destaca el 
mínimo en las curvas $R c$ - $t$ y $R$ - $t$ (fig. 5), ocasionado por el aumento súbito de concentración de álcalis en la fase líquida (fig. 10); el fin del fraguado medido con la aguja de Vicat coincide (por el aumento de la temperatura) con el del caso anterior.

\subsubsection{Clínker $\mathrm{H}$ con $50 \mathrm{~g}$ de yeso}

La temperatura ambiente en este caso coincide con las de los casos 3.1.1. y 3.1.3. Sin embargo, el fuerte aumento de la concentración de yeso provoca aquí la desaparición del mínimo en las curvas $R c-t$ y $R$-t (fig. 6), siendo sustituido por un aumento en la pendiente general de la curva, mayor que en los casos anteriores.

La hidratación de los silicatos, según la pendiente de la curva $R c-t$ en la figura 6, parece estar acelerada. Sin embargo, la figura 11 muestra que a las 24 horas aún queda yeso en la fase líquida y que se sigue formando ettringita. Se ha visto que la ettringita formada puede retrasar la hidratación de los silicatos, y lo hace mientras exista aluminato tricálcico y yeso sin combinar, pues en tales condiciones la ettringita en vías de formación es estable, y al formarse sobre cristales de aluminato tricálcico que rodean a los de los silicatos envuelve a éstos y los protege de la acción hidrolítica del agua.

Pero si se observan las curvas que indican la marcha de reacción del yeso y de los aluminatos (figs. 8, 9, 10 y 11), se aprecia que las cantidades que reaccionan por unidad de tiempo son cada vez menores a medida que aumenta la cantidad de yeso, ya que en la misma medida va siendo menor la pendiente de dichas curvas. Ello indica que la cantidad de ettringita formada por la unidad de tiempo es menor, y con ella la dificultad que opone a la hidratación de los silicatos.

Así se acelera la hidratación de éstos, por lo cual el fin del fraguado medido con la aguja de Vicat se observa antes, y la pasta endurece y toma resistencias mecánicas más rápidamente. En definitiva, debido a las circunstancias expuestas, el aumento de la proporción de yeso actúa como acelerador de la hidratación, pero sólo de la de los silicatos, y en particular de la del tricálcico.

La formación de álcalis solubles durante la hidratación es progresiva, durante las primeras 24 horas y no sufre aumentos bruscos, puesto que durante este tiempo la reacción del aluminato tricálcico con el yeso es más lenta que en los casos anteriores.

La solubilidad de los álcalis después de las 24 horas es mayor, debido a que entonces reacciona ya una cantidad mayor de aluminato.

En este caso, el segundo ciclo térmico (fig. 11) es debido solamente a la hidratación de la alita, y por esta causa las temperaturas del ciclo son menores.

La concentración de $\mathrm{Al}^{+++}$en la fase líquida baja lentamente durante la hidratación; al mismo tiempo, la concentración de $\mathrm{SiO}_{2}$ soluble se hace menor, ya que las reacciones de hidratación de la alita y la insolubilización de sus compuestos hidratados son más rápidas por las razones y mecanismos acabados de exponer.

Según se podría apreciar en la fotomicrografía de un clínker, los cristales de la alita están parcialmente rodeados de otros menores de aluminato tricálcico.

Al efectuar la molturación del clínker, en las partículas obtenidas la situación será semejante, y los cristales de la alita estarán también parcialmente rodeados de otros menores de aluminato tricálcico. 
En la pasta, la fase líquida que tiene yeso en disolución reacciona con las partes más externas de los pequeños cristales de aluminio tricálcico situados sobre la alita. Esta reacción puede efectuarse de dos maneras, en función de la concentración de yeso en la fase líquida:

1) Si la cantidad de yeso potencialmente soluble es grande y se alcanza pronto una elevada concentración de $\mathrm{SO}_{4}{ }^{*}$ en la fase líquida, la formación de ettringita será muy rápida y tendrá lugar prácticamente de modo simultáneo sobre todos los puntos de la superficie del cristal de $\mathrm{C}_{3} \mathrm{~A}$. Esta ettringita es muy insoluble y muy compacta e impermeable, por lo cual se alcanza rápidamente el recubrimiento total de todos los cristales de $\mathrm{C}_{3} \mathrm{~A}$, los cuales quedan así protegidos de una hidratación subsiguiente a fondo, mediante una capa muy delgada, pero muy eficaz a efectos aislantes, de ettringita.

Estas características de recubrimiento hacen que éste no afecte prácticamente a la hidratación de los cristales de $\mathrm{C}_{3} \mathrm{~S}$ rodeados de $\mathrm{C}_{3} \mathrm{~A}$, la cual transcurre independiente, ya que la alita apenas queda aislada del contacto con la fase líquida por la ettringita.

2) Si la cantidad de yeso potencialmente soluble es pequeña y se alcanza una concentración no muy elevada de $\mathrm{SO}_{4}{ }{ }^{2}$ en la fase líquida, la formación de la ettringita será continua, pero más lenta, y tendrá lugar preferentemente con carácter puntual o zonal selectivo, localizándose en los puntos más reactivos del cristal de $\mathrm{C}_{3} \mathrm{~A}$. Esta ettringita es menos insoluble, compacta e impermeable y, posiblemente, filamentosa o floculosa, por lo cual se alcanza más lentamente el recubrimiento de los cristales de $\mathrm{C}_{3} \mathrm{~A}$, los cuales quedan parcialmente protegidos de una hidratación subsiguiente, mediante una capa más gruesa, pero menos eficaz a efecto aislante, de ettringita. Las características del recubrimiento así formado hacen que éste pueda afectar a la hidratación de los cristales de $\mathrm{C}_{3} \mathrm{~S}$ rodeados de $\mathrm{C}_{3} \mathrm{~A}$, la cual transcurre con mayor lentitud, al quedar la alita parcialmente aislada del contacto con la fase líquida por la ettringita. Este aislamiento es llevado a cabo por la unión de los filamentos o copos de ettringita, formados sobre dos cristales contiguos de $\mathrm{C}_{3} \mathrm{~A}$, adyacentes a otro de $\mathrm{C}_{3} \mathrm{~S}$, formando un puente que recubre la superficie de éste intermedia entre los dos cristales de $\mathrm{C}_{3} \mathrm{~A}$.

En el primer caso los aluminatos se hidratan lentamente, y la alita, con rapidez; en el segundo caso se hidrata más rápidamente el aluminato tricálcico, y si la cantidad de éste es suficiente, continúa la degradación de la ettringita para formar monosulfoaluminatos, con lo cual también se puede hidratar finalmente la alita. Esta degradación puede suponerse por pasos sucesivos en la siguiente forma: en el primer lugar, la ettringita se formó por reacción entre $\mathrm{C}_{3} \mathrm{~A}$ y el yeso; al faltar éste o al faltar en la disolución una determinada concentración de él, necesaria para la estabilidad de la ettringita, ésta se hace inestable y se descompone en monosulfoaluminatos y yeso preciso para la estabilidad de la ettringita restante. Pero este yeso vuelve a reaccionar con más aluminato tricálcico para regenerar de nuevo la ettringita, mas al faltar por ello el yeso, ésta vuelve a ser inestable, descomponiéndose de nuevo en más monosulfoaluminato y más yeso, repitiéndose este ciclo continuamente hasta que todo el yeso y la ettringita han desaparecido y hasta que las cantidades del $\mathrm{C}_{3} \mathrm{~A}$ que ha reaccionado y de monosulfoaluminato que ha formado son máximas, quedando el monosulfoaluminato como única fase sulfatada final estable en el sistema del cemento hidratado. A partir de este momento, el resto del $\mathrm{C}_{3} \mathrm{~A}$ se hidrata directamente a $\mathrm{C}_{4} \mathrm{AH}_{13}$.

\subsection{Clínker I con distintas cantidades de yeso}

La mayor parte de los álcalis que contiene este clínker se encuentra en forma de sulfatos (cuadro III); al hidratarse el clínker no se desprenden, por tanto, óxidos alcalinos que aumenten la conductividad de la pasta. 
Dada la elevada solubilidad de los sulfatos (solubilidad del $\mathrm{SO}_{4} \mathrm{Na}_{2}=300 \mathrm{~g} / \mathrm{l}$; solubilidad del $\mathrm{SO}_{4} \mathrm{~K}_{2}=120 \mathrm{~g} / l$ ), éstos pasan rápidamente al agua de amasado.

Los aumentos de concentración de $\mathrm{Ca}(\mathrm{OH})_{2}$ observados en el agua de extracción de las pastas, cuando éstas se extraen a distintos tiempos de hidratación, según muestran las curvas de solubilidad de las figuras 16, 17 y 18, producirían aumentos correspondientes de la conductividad de la fase líquida de la pasta, si en dicha fase líquida aumentase también la concentración de $\mathrm{Ca}(\mathrm{OH})_{2}$ con el tiempo.

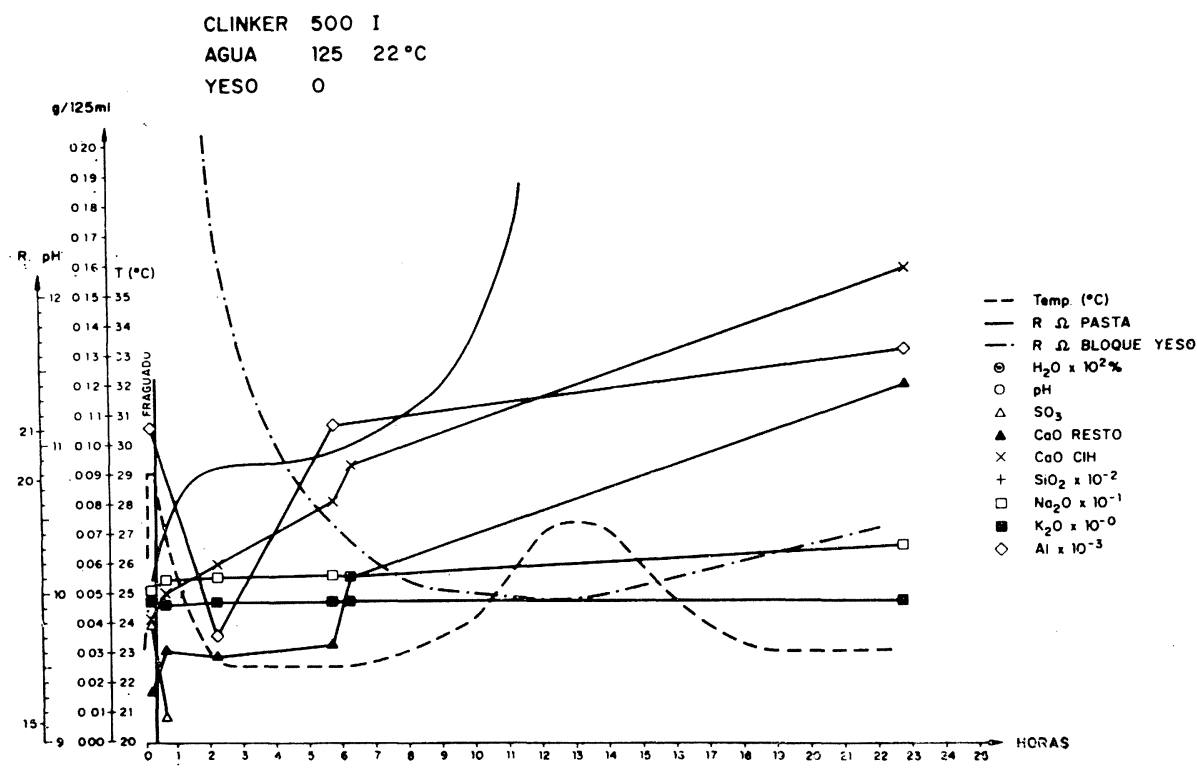

Fig. 16

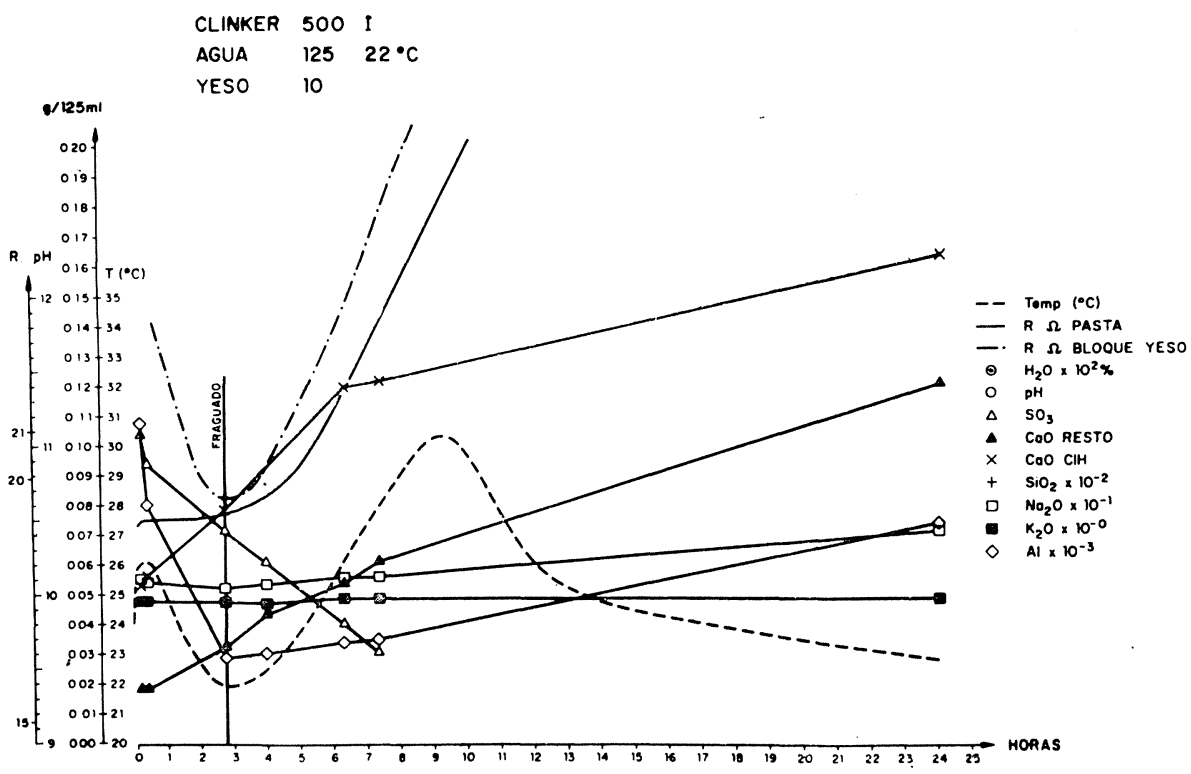

Fig. 17

Entonces cabría esperar la presencia del segundo mínimo en las curvas $R c-t$ y $R$-t. Ello no es así, de acuerdo con los resultados experimentales, porque la fase líquida de la pasta se encuentra saturada de $\mathrm{Ca}(\mathrm{OH})_{2}$ desde el principio, y los aumentos de concentra- 
ción de dicho componente en los extractos acuosos son ficticios y debidos a la solubilización del $\mathrm{Ca}(\mathrm{OH})_{2}$ existente en la fase sólida de la pasta, en la cual sí crece el $\mathrm{Ca}(\mathrm{OH})_{2}$ con el tiempo.

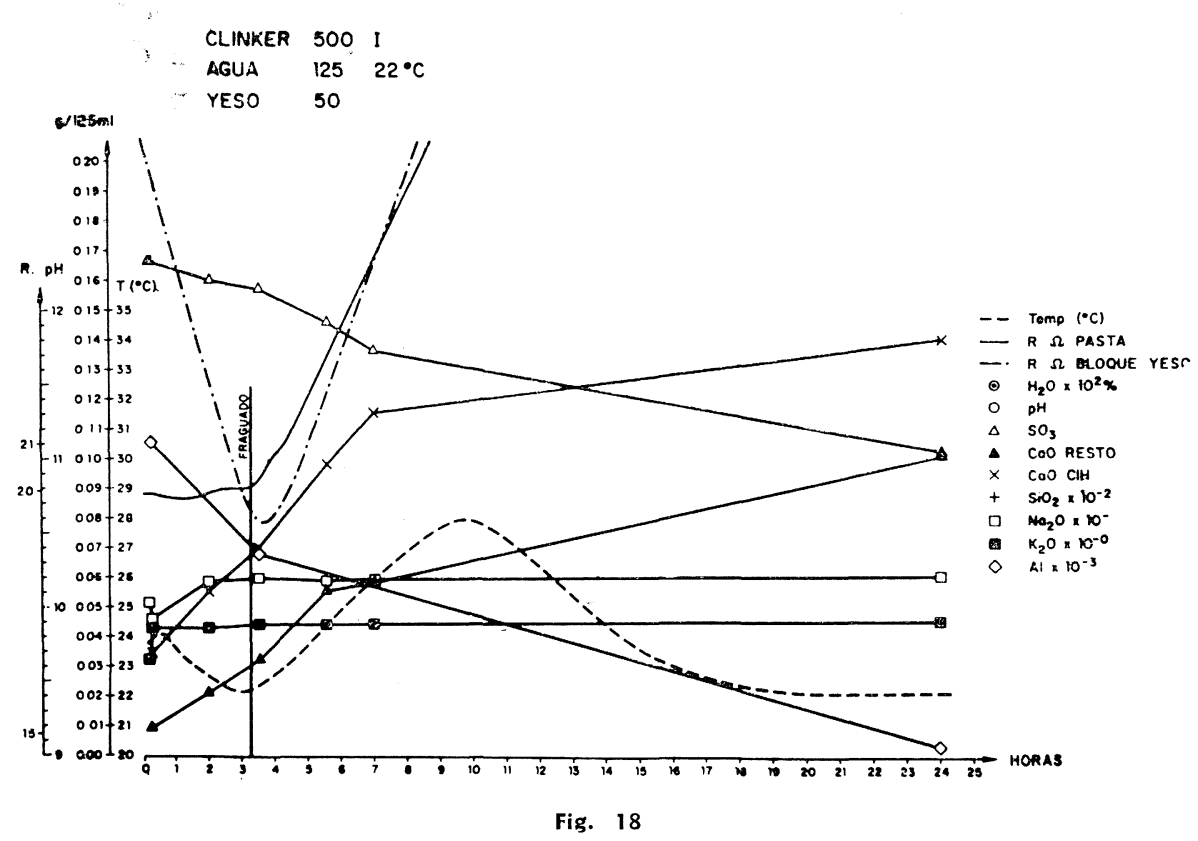

Así, pues, al no haber aumento de concentración de iones $\mathrm{OH}^{-}$en la fase líquida de la pasta a partir de un momento dado, tanto por hallarse saturada de $\mathrm{Ca}(\mathrm{OH})_{2}$ desde el principio como por encontrarse en este clínker los álcalis en forma de sulfatos y no liberarse más álcalis al reaccionar los aluminatos, tampoco hay aumento de conductividad en la fase líquida a partir de dicho momento, ni la consiguiente aparición del segundo mínimo en las curvas de resistencia eléctrica, a diferencia de lo que sucede en el clínker I.

Esto lo confirma también el hecho de que durante las primeras 24 horas de hidratación no hay variación de la concentración de álcalis en la fase líquida de la pasta.

En general, las curvas resistencia eléctrica-tiempo de las pastas del clínker I presentan valores más bajos que las correspondientes curvas del clínker $\mathrm{H}$, debido a que en el caso del clínker I la conductividad de la fase líquida de la pasta es mayor desde el principio por la presencia de iones sulfato y de cationes alcalinos procedentes de los sulfatos alcalinos que contiene el clínker.

Cuando se efectúa la hidratación del clínker sin añadirle yeso (fig. 16), se produce un primer ciclo térmico, durante el cual el $\mathrm{SO}_{4}{ }^{=}$de los sulfatos alcalinos, junto con el hidróxido cálcico procedente de una hidrólisis superficial de los silicatos y el aluminato tricálcico reaccionan dando ettringita, según el mecanismo explicado en el punto 3.1.6.

Se hidratan lentamente la alita y el aluminato tricálcico restante, dando origen su hidratación simultánea a la formación de un segundo ciclo térmico, claro y definido.

El fin del fraguado se da al principio de la prueba (fraguado rápido) por la poca protección que da la ettringita formada, ya que ésta no retrasa la hidratación del aluminato tricálcico.

Los resultados obtenidos de las curvas del agua no combinada (figs 16, 17 y 18) con el bloque de yeso están influenciados por la mayor concentración de sulfatos alcalinos que pasan inicialmente a disolución, y los valores de las curvas de resistencias son menores (tal como sucede también en las curvas $R$-t, según se acaba de indicar). 


\subsection{Cemento D}

En la figura 19 se observa la pequeña influencia que tiene la corrección de la resistencia por la temperatura, durante la formación del segundo mínimo, ya que unos $4^{\circ} \mathrm{C}$ de

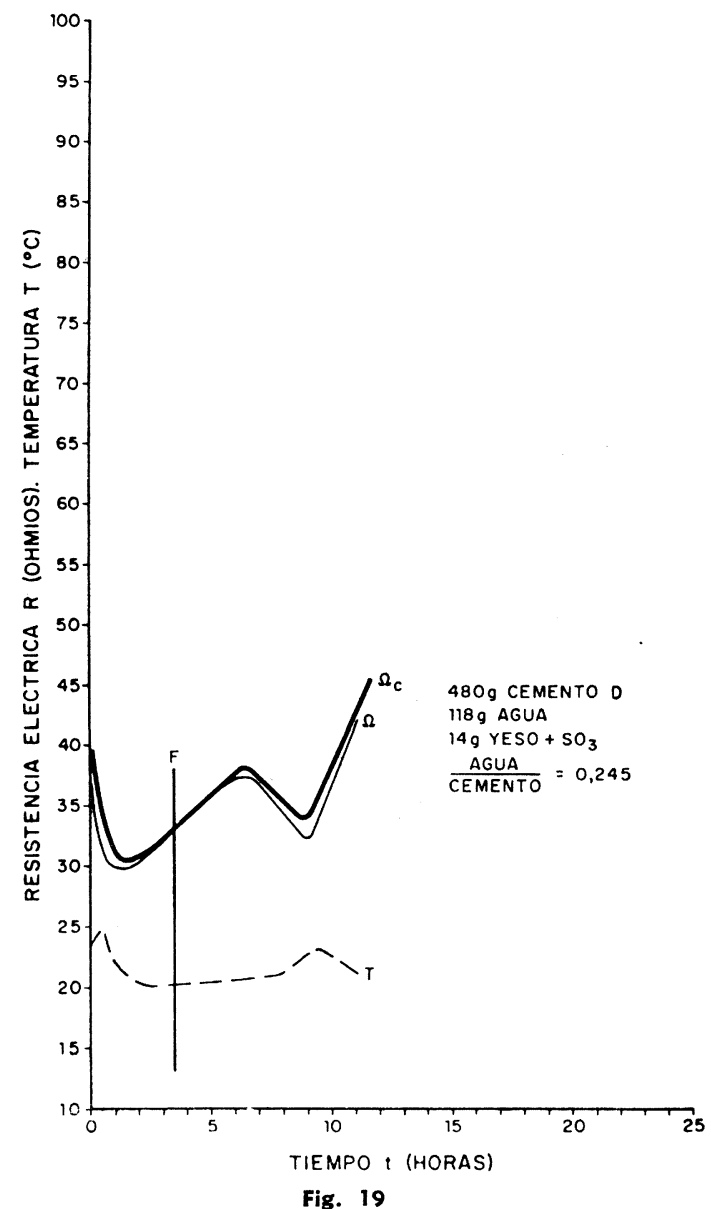
diferencia de temperatura durante el segundo ciclo térmico ocasionan una corrección de 0,08 ohmios en el valor correspondiente de la curva de resistencia; como en ésta hay una variación de 7 ohmios dicha variación no es debida sólo ni principalmente a la temperatura, que en este caso tiene una influencia insignificante.

El aumento en la concentración de álcalis (fig. 20 y cuadro III) nos explica nuevamente la causa del segundo mínimo en la curva de resistencia al aumentar en la fase líquida la concentración de iones $\mathrm{OH}^{-}$procedentes de los álcalis.

La concentración de $\mathrm{CaO}$ inicial, mayor que la de otros casos estudiados anteriormente, se explica como debida a la cal libre que contiene este cemento $(0,22 \%)$. Durante la hidratación, y coincidiendo con el segundo mínimo de la curva $R-t$ (fig. 20), hay una disminución de $\mathrm{CaO}$ soluble junto con un aumento en la concentración de $\mathrm{Al}^{+++}$, ocasionados ambos por el aumento de los álcalis desprendidos por la hidratación del aluminato tricálcico, al agotarse el $\mathrm{SO}_{4}{ }^{=}$en la fase líquida, de acuerdo con el mecanismo ya expuesto con detalle en el punto 3.1.6.

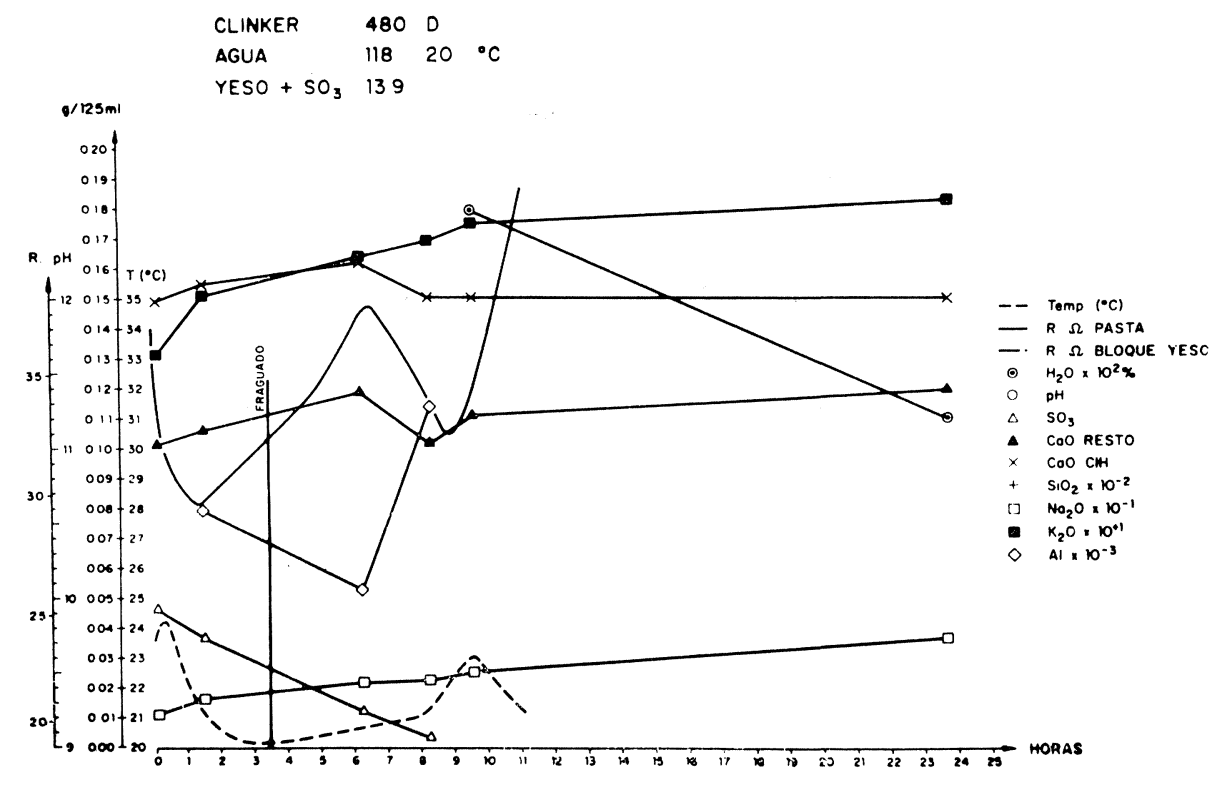

fig. 20 


\subsection{Hidratación del clínker y del cemento}

\subsubsection{Influencia de la solubilidad de los componentes hidratados}

Las disoluciones obtenidas por extracción con agua de las pastas de cementos tienen menor concentración en productos solubles que el agua de las pastas; parte o la totalidad de la sustancias que estaban en las pastas como sólidos se disuelven al aumentar la proporción de agua desde la que tenía la pasta $-2,5 \mathrm{ml}$ por cada $10 \mathrm{~g}$ de muestra de pasta- hasta los $125 \mathrm{ml}$ añadidos para extraer los productos solubles.

La alita, belita, ferritos y aluminatos como tales, y los productos de hidratación, como tobermorita, ettringita y monosulfoaluminatos, que tienen un producto de solubilidad de un orden menor a $10^{-6}$, no pasarán a la disolución al efectuar la extracción con el exceso de agua indicado.

El hidróxido cálcico $\left(\mathrm{Ps}_{\mathrm{s}}=5,5 \times 10^{-6}\right)$, el sulfato cálcico $\left(\mathrm{Ps}_{\mathrm{s}}=1,2 \times 10^{-6}\right)$, algunos aluminatos hidratados (con Ps del orden $10^{-6}$ ) pasan a la disolución junto con pequeñas proporciones de distintos ácidos silícicos; los sulfatos alcalinos, hidróxidos alcalinos y aphthitalitas son francamente solubles. Por tanto, es posible seguir el transcurso de algunas reacciones por análisis de los extractos acuosos.

Se vio anteriormente que la desaparición del $\mathrm{SO}_{3}$ soluble de la fase líquida de la pasta indica la total reacción del yeso con el $\mathrm{C}_{3} \mathrm{~A}$; así, por cada mol de $\mathrm{SO}_{3}$ que se elimine de la disolución, en la pasta reaccionará $1 / 3$ de mol de $\mathrm{C}_{3} \mathrm{~A}$ formando ettringita. Cuando la fase líquida no tenga $\mathrm{SO}_{3}$ reaccionará la ettringita, según se vio, con más $\mathrm{C}_{3} \mathrm{~A}$, dando monosulfoaluminato; esta reacción se podrá seguir por difracción de rayos $\mathrm{X}$. Cuando desaparezca la ettringita de la fase sólida, habrá reaccionado por cada mol de $\mathrm{SO}_{3}$ original un mol de $\mathrm{C}_{3} \mathrm{~A}$; sin embargo, esta reacción no es rápida en los cementos portland, y al cabo de años de hidratación aún es posible encontrar ettringita.

Por determinación del hidróxido cálcico en la pasta (si se conocen los contenidos de silicatos en el clínker) es posible obtener una orientación sobre la forma y velocidad de hidratación de los silicatos:

$$
2 \mathrm{x} \cdot \mathrm{C}_{3} \mathrm{~A}+2 \mathrm{y} \cdot \mathrm{C}_{2} \mathrm{~S}+(5 \mathrm{x}+3 \mathrm{y}) \mathrm{H} \rightarrow 2(\mathrm{x}+\mathrm{y}) \mathrm{C}_{3} \mathrm{~S}_{2} \mathrm{H}_{2}+(3 \mathrm{x}+\mathrm{y}) \mathrm{CH}
$$

siendo $\mathrm{x}=\% \mathrm{C}_{3} \mathrm{~S} ; \mathrm{y}=\% \mathrm{C}_{2} \mathrm{~S}$.

Mediante el análisis de los óxidos de sodio y de potasio solubles, se puede apreciar si los álcalis se encuentran en forma de sulfatos, en cuyo caso aparecen durante los primeros minutos de hidratación. Un aumento de concentración de álcalis en la fase líquida durante el segundo máximo térmico indica que los álcalis están combinados con las fases del clínker en forma de óxidos, principalmente con el $\mathrm{C}_{3} \mathrm{~A}$. El aumento mutuamente paralelo de los álcalis en la fase líquida, según las curvas de solubilidad, muestra que tanto el $\mathrm{Na}_{2} \mathrm{O}$ como el $\mathrm{K}_{2} \mathrm{O}$ forman un compuesto doble con una fase del clínker.

Un aumento de la concentración de álcalis solubles, proporcional al aumento o disminución de otro componente en la disolución, ayuda a saber con cuál fase del clínker están combinados.

\section{5. $\mathrm{SO}_{3}$ y yeso óptimo}

Lerch (1) considera que la cantidad óptima de yeso que se debe añadir a un clínker es la que permite combinarse todo el $\mathrm{SO}_{3}$ antes de las 36 horas. La formación de ettringita es precisamente la que insolubiliza el $\mathrm{SO}_{3}$. 
Las explicaciones que existen en la actualidad sobre la hidratación del cemento portland no tienen en cuenta la procedencia del $\mathrm{SO}_{3}$, ya que consideran la totalidad del $\mathrm{SO}_{3}$ sin distinguir: el del yeso añadido, el que puede contener el clínker en forma de sulfato cálcico y el que se encuentra en él en forma de sulfatos alcalinos.

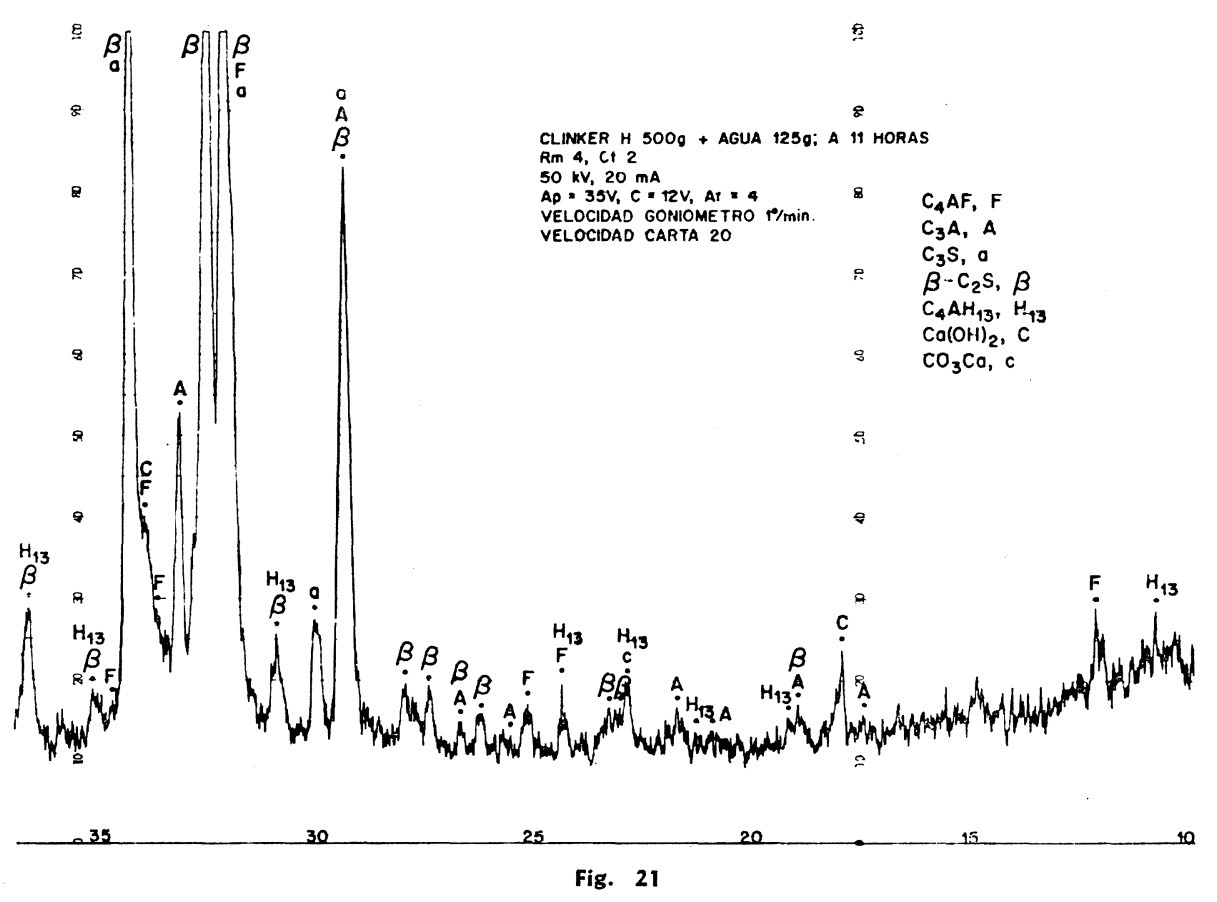

En el clínker, los álcalis se encuentran en forma de sulfatos si hay $\mathrm{SO}_{3}$ suficientemente

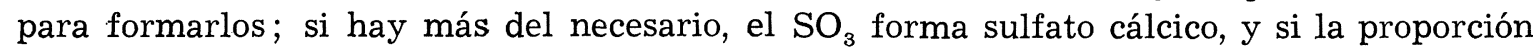
de $\mathrm{SO}_{3}$ es insuficiente o nula, existirán álcalis en forma de óxidos combinados con las fases del clínker (12).

Los sulfatos alcalinos que contenga el clínker o los que se formen por reacción entre los hidróxidos alcalinos y el $\mathrm{SO}_{3}$ del yeso en el agua de amasado aceleran la hidratación y formación de los sulfoaluminatos.

Agotado el $\mathrm{SO}_{3}$ soluble por haber reaccionado el yeso, aumentará la concentración de $\mathrm{OH}^{-3}$ de la disolución, precipitará la cal y aumentará la solubilidad de la alúmina, favoreciéndose la formación de aluminato tetracálcico hidratado, siendo ésta la causa del aumento del $\mathrm{Al}^{+++}$soluble en los extractos acuosos, al desaparecer el $\mathrm{SO}_{3}$ soluble.

$\mathrm{Si}$ al clínker no se le ha añadido yeso o la proporción añadida es muy pequeña, el $\mathrm{SO}_{3}$ reacciona en su totalidad para formar ettringita al comienzo de la hidratación; los aluminatos en disolución o insolubles, como el $\mathrm{C}_{4} \mathrm{AH}_{13}$, disminuyen la solubilidad de los silicatos por un mecanismo análogo al de los sulfatos del punto 3.1.6., por lo cual se retrasa la hidratación de éstos y también el fraguado.

En las curvas $R$ - $t$ y $T$ - $t$ estudiadas se observa que al aumentar la proporción de yeso añadido al clínker, a partir de una concentración dada de yeso para cada uno, hay un adelanto en la aparición del segundo ciclo térmico y también en la subida final de la resistencia eléctrica. La cantidad precisa de yeso para que la aparición del segundo ciclo térmico tarde en darse es la más adecuada, es decir, hay que evitar que el yeso actúe como acelerador. 
Para que se combine todo el yeso con el aluminato tricálcico antes de las 36 horas de hidratación a la temperatura de $20^{\circ} \mathrm{C}$ (13) es preciso que la cantidad de yeso sea menor de $45 \mathrm{~g}$ por cada $100 \mathrm{~g}$ de $\mathrm{C}_{3} \mathrm{~A}$, lo cual nos da la cantidad máxima de yeso que se debe añadir a un clínker. Hay que tener en cuenta que la cantidad deberá ser mayor si el clínker contiene sulfatos alcalinos, para conseguir una concentración más alta de yeso en la fase líquida y que se retrase la hidratación del $\mathrm{C}_{3} \mathrm{~A}$. En la hidratación del clínker I que contiene sulfatos alcalinos hubo fraguado rápido; en la hidratación del clínker $\mathrm{H}$ que no tenía sulfatos alcalinos, el fin del fraguado se dio a las 2 horas $45 \mathrm{~min}$.

Igualmente, se ve, en los casos de los cementos estudiados, que la cantidad de yeso óptimo está entre $3 \mathrm{~g}$ y $10 \mathrm{~g}$ de yeso por cada $100 \mathrm{~g}$ de clínker, para contenidos de $\mathrm{C}_{3} \mathrm{~A}$ del $10 \%$. Cuando el yeso (10 g) se pasa del óptimo, se observa que hay un adelanto en la formación del segundo ciclo térmico.

Con la citada concentración de yeso se obtiene el máximo desprendimiento de calor durante un tiempo mayor. La pasta durante este tiempo no se encuentra totalmente fraguada, y por ello no se producirán efectos nocivos sobre la resistencia mecánica; el cemento no sufrirá expansiones posteriores y será más compacto y resistente, incluso a posteriores ataques químicos.

\subsection{Hidratación de los silicatos y aluminatos}

Las reacciones de formación de sulfoaluminatos contribuyen a dar una primera trabazón a la pasta; el aumento en la concentración de $\mathrm{CaO}$ en el entorno del fin del fraguado medido con la aguja de Vicat muestra que la hidratación de los silicatos y también la cristalización del $\mathrm{Ca}(\mathrm{OH})_{2}$ contribuyen a dar mayor consistencia y rigidización a la pasta.

A partir del segundo máximo térmico, se detecta por difracción de rayos $\mathrm{X}, \mathrm{Ca}(\mathrm{OH})_{2}$ cristalizado; la aguja de Vicat no deja huella entonces en la pasta, ya que ésta tiene la rigidez de un sólido, debido a las formaciones cristalinas y de tobermorita.

Los aluminatos, como vimos repetidamente, pasan parcialmente a la disolución, hasta que se eliminan de ésta en forma de ettringita. La formación exotérmica del trisulfoaluminato cristalino acelera la formación de la tobermorita, contribuyendo también a la rigidez, y la solubilidad de la alúmina aumenta nuevamente, una vez consumido el $\mathrm{SO}_{3}$, al disolverse de nuevo el $\mathrm{C}_{3} \mathrm{~A}$, según vimos en el mecanismo explicado en el punto 3.1.6.

\section{3.\%. Influencia de los álcalis en las reacciones de hidratación}

La solubilidad en agua del yeso empleado resultó ser de $2,3 \mathrm{~g} / l$. Al añadir a una disolución de este yeso sulfato potásico, la solubilidad del yeso disminuyó a $0,3 \mathrm{~g} / \mathrm{l}$; su solubilidad en una disolución saturada de hidróxido cálcico fue de $2,2 \mathrm{~g} / l$.

Si a una disolución saturada de yeso se le añadían sulfatos alcalinos, no precipitaba yeso, y, en cambio, si la disolución saturada era de hidróxidos alcalinos, precipitaba, al añadir yeso, hidróxido cálcico.

Durante la preparación de ettringita se observó que éstas podían coexistir con sulfato sódico o potásico e incluso con aphthitalita, aunque dichos compuestos no eran admitidos en la composición de las ettringitas y se separaban de las pastas en condiciones favorables. 
Entonces los sulfatos alcalinos también podían dar lugar al reaccionar con el $\mathrm{C}_{3} \mathrm{~A}$ a la formación de ettringita y del correspondiente hidróxido, según:

$$
\begin{aligned}
& 3 \mathrm{Ns}+3 \mathrm{CH}+\mathrm{C}_{3} \mathrm{~A}+32 \mathrm{H} \rightarrow \mathrm{C}_{6} \mathrm{As}_{3} \mathrm{H}_{32}+\mathrm{NH} \\
& 3 \mathrm{Ks}+3 \mathrm{CH}+\mathrm{C}_{3} \mathrm{~A}+32 \mathrm{H} \rightarrow \mathrm{C}_{6} \mathrm{As}_{3} \mathrm{H}_{32}+\mathrm{KH}
\end{aligned}
$$

Los álcalis procedentes de las fases del clínker y de las reacciones anteriores pasan a la fase líquida disminuyendo la solubilidad del hidróxido cálcico, según:

$$
\begin{aligned}
& \mathrm{NH} \text { (disuelto) }+\mathrm{CH} \text { (disuelto) } \rightarrow \mathrm{NH} \text { (disuelto) }+\mathrm{CH} \text { (insoluble) } \\
& \mathrm{KH} \text { (disuelto) }+\mathrm{CH} \text { (disuelto) } \rightarrow \mathrm{KH} \text { (disuelto) }+\mathrm{CH} \text { (insoluble) }
\end{aligned}
$$

Al terminar las reacciones [1] y [2] se aceleran las siguientes:

$$
\begin{aligned}
2 \mathrm{KC}_{23} \mathrm{~S}_{12}+36 \mathrm{H} & \rightarrow 2 \mathrm{KH}+12 \mathrm{C}_{3} \mathrm{~S}_{2} \mathrm{H}_{2}+10 \mathrm{CH} \\
2 \mathrm{C}_{3} \mathrm{~A}+\mathrm{C}_{6} \mathrm{As}_{3} \mathrm{H}_{32}+4 \mathrm{H} & \rightarrow 3 \mathrm{C}_{4} \mathrm{AsH}_{12} \\
2 \mathrm{C}_{3} \mathrm{~S}+5 \mathrm{H} & \rightarrow \mathrm{C}_{3} \mathrm{~S}_{2} \mathrm{H}_{2}+3 \mathrm{CH} \\
2 \mathrm{C}_{2} \mathrm{~S}+3 \mathrm{H} & \rightarrow \mathrm{C}_{3} \mathrm{~S}_{2} \mathrm{H}_{2}+1 \mathrm{CH} \\
2 \mathrm{NC}_{8} \mathrm{~A}_{3}+2 \mathrm{C}_{6} \mathrm{As}_{3} \mathrm{H}_{32}+2 \mathrm{CH}+10 \mathrm{H} & \rightarrow 9 \mathrm{C}_{4} \mathrm{AsH}_{12}+2 \mathrm{NH} \\
2 \mathrm{KC}_{3} \mathrm{~A}+3 \mathrm{C}_{6} \mathrm{As}_{3} \mathrm{H}_{32}+2 \mathrm{CH}+10 \mathrm{H} & \rightarrow 9 \mathrm{C}_{4} \mathrm{AsH}_{12}+2 \mathrm{KH}
\end{aligned}
$$

y cuando queda aluminato tricálcico sin reaccionar por haberse agotado el yeso, reacciona según:

$$
\begin{aligned}
\mathrm{C}_{3} \mathrm{~A}+\mathrm{CH}+12 \mathrm{H} & \rightarrow \mathrm{C}_{4} \mathrm{AH}_{13} \\
\mathrm{NC}_{8} \mathrm{~A}_{3}+4 \mathrm{CH}+33 \mathrm{H} & \rightarrow 3 \mathrm{C}_{4} \mathrm{AH}_{13}+\mathrm{NH} \\
\mathrm{KC}_{8} \mathrm{~A}_{3}+4 \mathrm{CH}+33 \mathrm{H} & \rightarrow 3 \mathrm{C}_{4} \mathrm{AH}_{13}+\mathrm{KH}
\end{aligned}
$$

todas las reacciones productoras de hidróxidos alcalinos aumentan la solubilidad de la alúmina, aceleran la formación de sulfoaluminatos y retardan la hidratación de los silicatos, por impedir o dificultar el paso de $\mathrm{Ca}(\mathrm{OH})_{2}$ a la fase líquida, oponiéndose así a la hidrólisis de aquéllos.

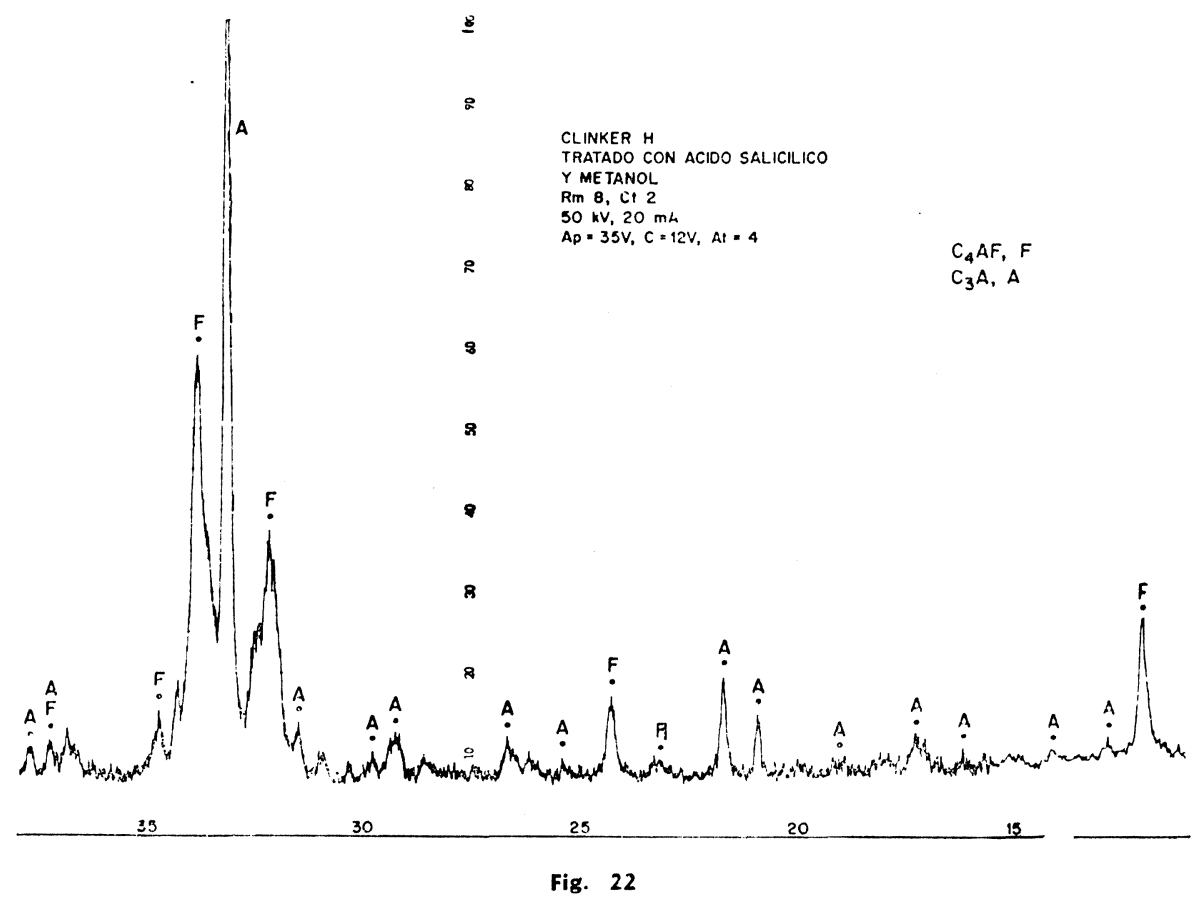




\subsection{Mínimos en las curvas R-t}

En los cementos preparados con el clínker $H$, los valores de las curvas $R$ - $t$ son algo menores con este clínker que los de los otros cementos, debido a la pequeña proporción de álcalis en el agua de amasado.

Durante la hidratación del clínker $\mathrm{H}$ hay un ligero aumento en la fase líquida de $\mathrm{Na}_{2} \mathrm{O}$ y otro mayor de $\mathrm{K}_{2} \mathrm{O}$. En los extractos líquidos de la pasta del clínker $\mathrm{H}$ no se encontró $\mathrm{SO}_{3}$, lo cual demuestra que el clínker tampoco lo tiene.

Conforme se produce ettringita a partir del aluminato tricálcico, aumentan los álcalis solubles y sus curvas de solubilización son paralelas.

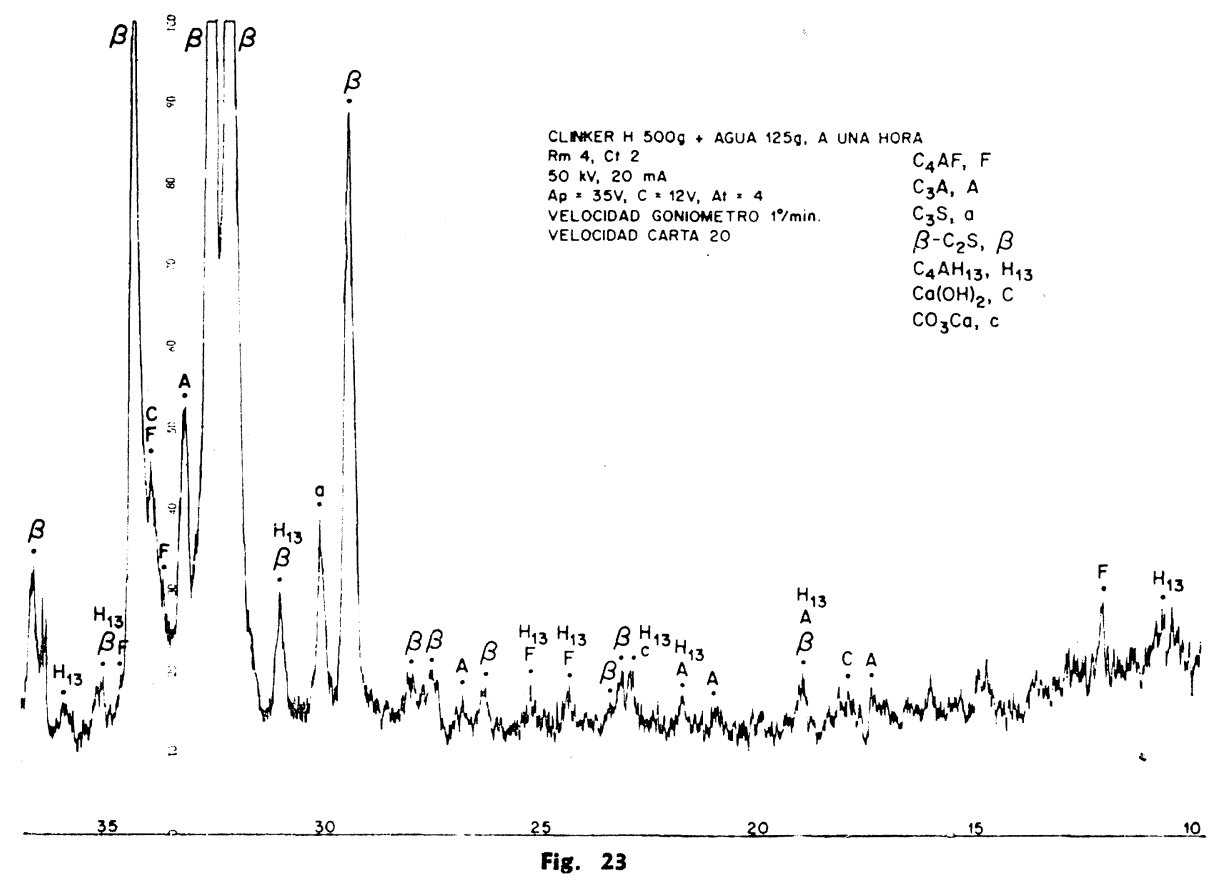

Se determinó por fotometría de llama la cantidad de álcalis del clínker $\mathrm{H}$ y de las fases $\mathrm{C}_{4} \mathrm{AF}+\mathrm{C}_{3} \mathrm{~A}$ del mismo (obtenidas mediante extracción con ácido salicílico y metanol (14) y del $C_{3} A$ (separado con agua hirviendo del $C_{4} A F$ ), y se obtuvieron los siguientes resultados:

\begin{tabular}{|c|c|c|c|}
\hline & Clinker $\mathbf{H}$ & $\mathbf{C}_{4} \mathbf{A F}+\mathbf{C}_{3} \mathbf{A}$ & $\mathbf{C}_{3} \mathbf{A}$ \\
\hline $\begin{array}{lllllllllllllll}\mathrm{Na}_{2} \mathrm{O} & (\%) & \ldots & \ldots & \ldots & \ldots & \ldots & \ldots & \ldots & \ldots & \ldots & \ldots & \ldots & \ldots & \ldots\end{array}$ & 0,07 & 0,11 & 0,29 \\
\hline $\begin{array}{lllllllllllllll}\mathrm{K}_{2} \mathrm{O} & (\%) & \ldots & \ldots & \ldots & \ldots & \ldots & \ldots & \ldots & \ldots & \ldots & \ldots & \ldots & \ldots & \ldots\end{array}$ & 0,19 & 0,27 & 0,58 \\
\hline
\end{tabular}

lo cual demuestra que ambos álcalis están combinados con el $\mathrm{C}_{3} \mathrm{~A}$, conclusión que ya se podía obtener de las curvas de solubilización al ser paralelas.

Las variaciones de la concentración de álcalis en los $125 \mathrm{ml}$ del extracto acuoso son relativamente pequeñas, mas en el agua de amasado son unas setenta veces mayores y lo suficientemente elevadas como para ocasionar un aumento en la conductividad y producir el segundo mínimo en las curvas $R$-t. 
En el clínker I, los álcalis se encuentran en forma de sulfatos, y posiblemente una pequeña proporción del $\mathrm{K}_{2} \mathrm{O}$ estabiliza la forma beta del silicato bicálcico, y una parte mínima de los álcalis también se encuentra combinada con el aluminato tricálcico.

La falta del segundo mínimo en la curva $R$ - $t$ durante el segundo ciclo térmico del clínker I se explicó como debida a la ausencia de álcalis en forma de óxidos en la proporción suficiente para ocasionar un cambio en la conductividad; la elevada concentración de sulfatos alcalinos explica la aparición de éstos y de la aphthitalita.

En el cemento D, la proporción de sulfatos alcalinos es apreciable, pero menor que la del clínker I; sin embargo, es fácil observar en las curvas de solubilización que el clínker de este cemento tiene álcalis combinados en los componentes $\mathrm{NC}_{8} \mathrm{~A}_{3}, \mathrm{KC}_{8} \mathrm{~A}_{3} \mathrm{y} \mathrm{KC}_{23} \mathrm{~S}_{12}$, ya que aumentan los álcalis durante el segundo ciclo térmico, y que aparece un mínimo muy marcado en la curva $R$-t.

Si de la cantidad inicial de álcalis solubles se deduce su tanto por ciento respecto al clínker en forma de sulfatos, todavía destaca más que el segundo mínimo de las curvas $R-t$ es debido a los hidróxidos alcalinos, sobre todo los que están combinados con el $\mathrm{C}_{3} \mathrm{~A}$.

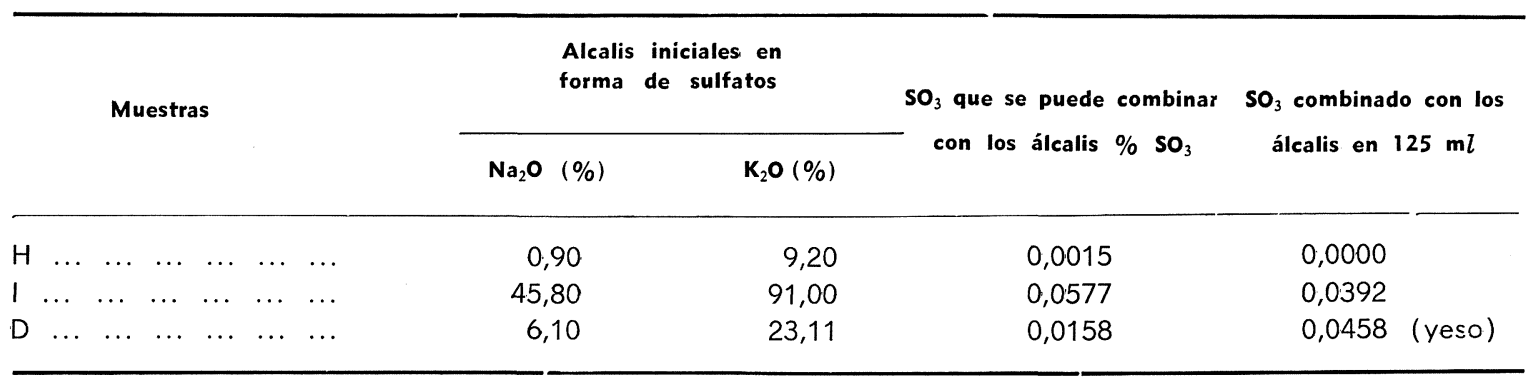

Los clínkeres $\mathrm{H}$ y del cemento $\mathrm{D}$ tienen, por lo tanto, una fuerte proporción de sus álcalis en forma de hidróxidos, mientras que en el clínker I sólo hay un $54 \%$ de $\mathrm{Na}_{2} \mathrm{O}$ en dicha posible forma.

Se eliminan como causas posibles de la aparición del segundo mínimo de las curvas $R-t$ :

i) La alúmina solubilizada, por su pequeña proporción durante el segundo ciclo térmico (figs. 10, 12 y 20).

ii) La cal de hidrólisis, por encontrarse siempre en estado de saturación (figs. 10, 12 y 20$)$.

iii) Las variaciones de humedad, ya que el agua no combinada disminuye linealmente (figs., 10 y 12).

iv) Los sulfatos alcalinos, pues en este caso no varía la concentración de álcalis durante la hidratación (cuadro III, clínker I).

v) El endurecimiento mecánico, por ser progresivo.

vi) La influencia de la temperatura, pues dicha influencia fue descartada al efectuar las correcciones con las que se obtuvieron las curvas $R c-t$ (figs. 2, 3, 4, 5 y 19).

De acuerdo con lo dicho anteriormente, el mínimo de resistencia eléctrica representado en las curvas $R$ - $t$ y $R c-t$ que aparece durante el segundo ciclo térmico se produce por un aumento en la concentración de $\mathrm{OH}^{-}$suministrado por la hidratación de los compuestos alcalinos del aluminato tricálcico principalmente, y en menor proporción por el compuesto potásico del silicato bicálcico, en forma de hidróxidos alcalinos que pasan a la fase líquida en un tiempo pequeño. 
Al aumentar el yeso en relación con el aluminato tricálcico disminuye la velocidad de reacción de éste y se retrasa el fraguado y la aparición del segundo ciclo térmico. Como los suministradores de álcalis se hidratan durante un tiempo mayor y pasan, por lo tanto, en mayor cantidad a la fase líquida, antes de la desaparición final del $\mathrm{SO}_{3}$ habrá una cantidad mayor de álcalis. La brusca hidratación que experimenta entonces el aluminato, al desaparecer el $\mathrm{SO}_{3}$, proporciona en el momento de producirse el segundo máximo térmico una cantidad menor de álcalis, y tanto menor cuanto más tarde en producirse y cuanto menor sea la cantidad de álcalis que contenga el clínker en forma de óxidos combinados; lo cual es causado por hidratarse en dicho momento una cantidad menor de aluminato.

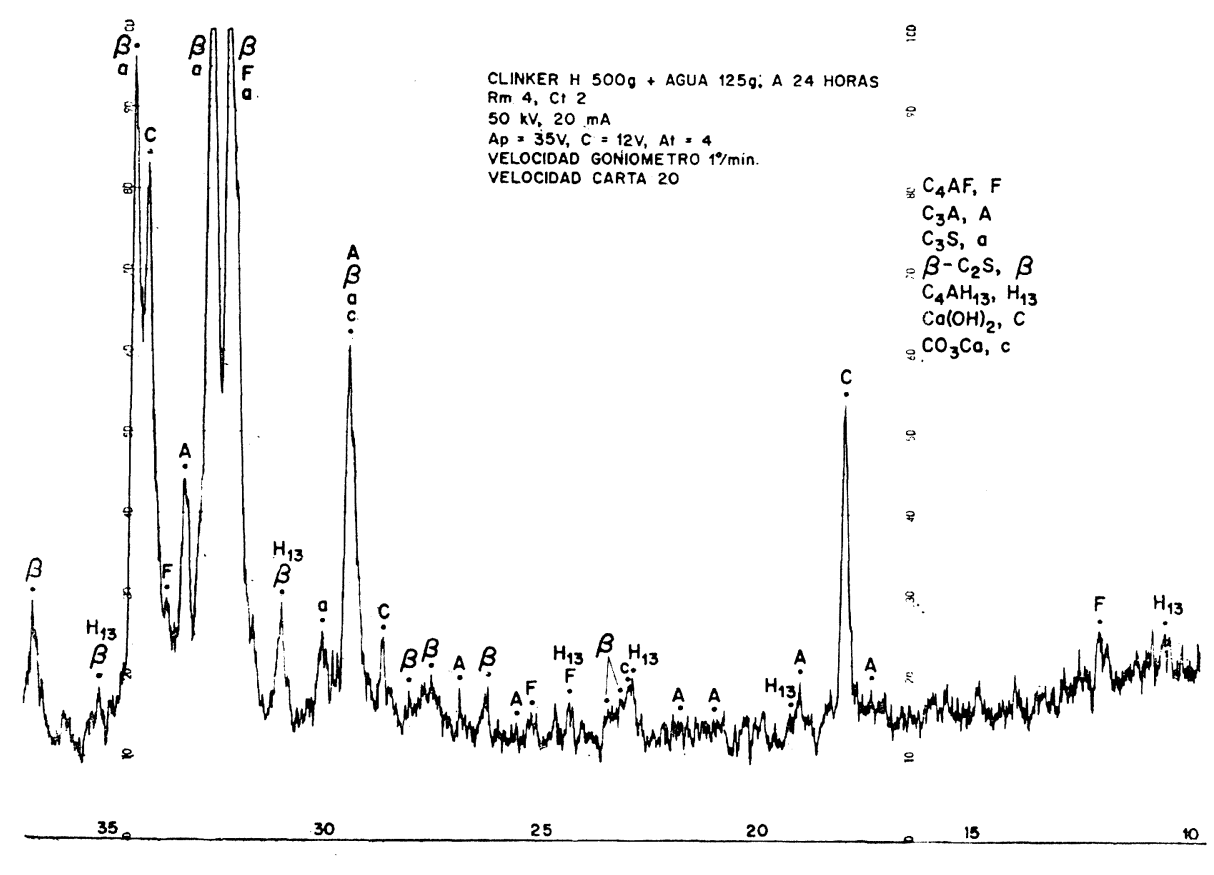

Fig. 24

$\mathrm{Si}$ a lo anteriormente dicho sumamos el efecto ocasionado por la mayor rigidez que tiene la pasta al aumentar el tiempo de hidratación, tendremos la explicación de que los mínimos sean menores o incluso de que desaparezcan a partir de un tiempo dado de hidratación.

Simultáneamente, también serán más difíciles de registrar, al suponer cambios de resistencia más pequeños en valores más altos de resistencia.

\section{CONCLUSIONES}

1) Se ha confirmado la aparición de la ettringita como primer producto de la reacción del aluminato tricálcico con el yeso y de los difractogramas obtenidos se deduce la aparición más tardía del monosulfoaluminato cálcico hidratado. La formación de los sulfoaluminatos en general y sus efectos sobre la velocidad de hidratación se ha explicado basándose en la estructura y cantidad de los componentes del clínker y de la cantidad de yeso presente en la fase líquida. 
2) El segundo mínimo que aparece en las curvas de resistencia eléctrica-tiempo de las pastas de cemento portland es provocado por un aumento de la concentración de hidróxidos alcalinos procedentes de las fases anhidras del clínker (principalmente del $\mathrm{NC}_{8} \mathrm{~A}_{3}$ y $\mathrm{KC}_{8} \mathrm{~A}_{3}$ ), en la fase líquida.

Cuando los álcalis se encuentran en el clínker combinados en forma de sulfatos, caso cada día más frecuente en clínkeres obtenidos con combustibles líquidos y con determinados tipos de hornos, las pastas de estos clínkeres no presentan el segundo mínimo de resistencia eléctrica, porque la concentración de sulfatos alcalinos, fácilmente solubles, se mantiene constante desde el principio de la hidratación.

3) El aumento en la cantidad de yeso añadida al clínker produce una disminución en la velocidad de hidratación del aluminato tricálcico, pero no en la de la alita, lo cual se refleja en las curvas de resistencia eléctrica-tiempo y de temperatura-tiempo de la pasta. Así se explica la atenuación o desaparición del segundo mínimo de las curvas de resistencia eléctrica-tiempo, correspondiente a una rigidez elevada de la pasta, junto con un menor paso y cantidad de álcalis a la fase líquida, ya que el primero está frenado y la segunda restringida por la mayor concentración de yeso.

4) Lo que antecede permite establecer como contenido óptimo de yeso en una pasta aquel que provoca la aparición más tardía del máximo de la curva $T-t$ y de la subida final de resistencia o de la aparición del segundo mínimo en la curva $R$-t.

\section{B I B L I O G R A F I A}

(1) W. LeRch.: P. C. A. Res. Dept. Bull., 12 (1942).

(2) J. Calleja.: Monografía núm. 109 del I.E.T.c.c. (1950).

(3) J. Calleja. : Monografía núm. 134 del I.E.T.c.c. (1953).

(4) J. Calleja.: Journal Amer. Concret. Inst., 24, 329 (1952).

(5) J. M. ToBio.: ION, núm. 209 (1958).

(6) F. Triviño.: ION. vol. XXXI, págs 231-235 (1971).

(7) F. Triviño.: ION, vol. XXXI, págs. 572-577 (1971).

(8) P. C. C. H. 64.: Normas y manuales del I.E.T.c.c. (1964).

(9) F. Triviño.: "Revista de Ciencia Aplicada", núm. 111 (1966).

(10) J. Calleja, J. M. Fernandez y F. Triviño.: "Revista de Ciencia Aplicada", núms. 99 y 100 (1964).

(11) F. Triviño.: Monografía núm. 246 del I.E.T.c.c. (1965).

(12) Calleja.: "Revista de Ciencia Aplicada", núm. 76 (1960).

(13) F. Triviño.: ION, vol. XXXII, págs. 525-531 (1972).

(14) F. Triviño, : ION, vol. XXXI, págs. 628-629 (1971).

\section{AGRADECIMIENTO}

El autor manifiesta su especial agradecimiento al profesor don José Calleja por la dirección, corrección y orientaciones prestadas en el desarrollo de este trabajo; al profesor don Angel Vian, por sus opiniones y consejos; al ingeniero técnico don José Manuel Fernández París, por la realización práctica del análisis microscópico de los clínkeres, y a la Dirección del Instituto Eduardo Torroja por las numerosas facilidades de medios e instrumentación utilizados. 